\title{
Interventions to improve team effectiveness within health care: a systematic review of the past decade
}

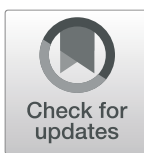

Martina Buljac-Samardzic ${ }^{1 *}$, Kirti D. Doekhie ${ }^{2}$ and Jeroen D. H. van Wijngaarden ${ }^{3}$

\begin{abstract}
Background: A high variety of team interventions aims to improve team performance outcomes. In 2008, we conducted a systematic review to provide an overview of the scientific studies focused on these interventions. However, over the past decade, the literature on team interventions has rapidly evolved. An updated overview is therefore required, and it will focus on all possible team interventions without restrictions to a type of intervention, setting, or research design.
\end{abstract}

Objectives: To review the literature from the past decade on interventions with the goal of improving team effectiveness within healthcare organizations and identify the "evidence base" levels of the research.

Methods: Seven major databases were systematically searched for relevant articles published between 2008 and July 2018. Of the original search yield of 6025 studies, 297 studies met the inclusion criteria according to three independent authors and were subsequently included for analysis. The Grading of Recommendations, Assessment, Development, and Evaluation Scale was used to assess the level of empirical evidence.

Results: Three types of interventions were distinguished: (1) Training, which is sub-divided into training that is based on predefined principles (i.e. CRM: crew resource management and TeamSTEPPS: Team Strategies and Tools to Enhance Performance and Patient Safety), on a specific method (i.e. simulation), or on general team training. (2) Tools covers tools that structure (i.e. SBAR: Situation, Background, Assessment, and Recommendation, (de)briefing checklists, and rounds), facilitate (through communication technology), or trigger (through monitoring and feedback) teamwork. (3) Organizational (re)design is about (re)designing structures to stimulate team processes and team functioning. (4) A programme is a combination of the previous types. The majority of studies evaluated a training focused on the (acute) hospital care setting. Most of the evaluated interventions focused on improving non-technical skills and provided evidence of improvements.

Conclusion: Over the last decade, the number of studies on team interventions has increased exponentially. At the same time, research tends to focus on certain interventions, settings, and/or outcomes. Principle-based training (i.e. CRM and TeamSTEPPS) and simulation-based training seem to provide the greatest opportunities for reaching the improvement goals in team functioning.

Keywords: Systematic review, Healthcare teams, Intervention, Team training, Team tool, Team effectiveness, Team performance

\footnotetext{
* Correspondence: BULJAC@ESHPM.EUR.NL

${ }^{1}$ Erasmus School of Health Policy \& Management, Erasmus University

Rotterdam, Bayle building, p.o. box 1738, 3000, DR, Rotterdam, The

Netherlands

Full list of author information is available at the end of the article
}

(c) The Author(s). 2020 Open Access This article is distributed under the terms of the Creative Commons Attribution 4.0 International License (http://creativecommons.org/licenses/by/4.0/), which permits unrestricted use, distribution, and reproduction in any medium, provided you give appropriate credit to the original author(s) and the source, provide a link to the Creative Commons license, and indicate if changes were made. The Creative Commons Public Domain Dedication waiver (http://creativecommons.org/publicdomain/zero/1.0/) applies to the data made available in this article, unless otherwise stated. 


\section{Introduction}

Teamwork is essential for providing care and is therefore prominent in healthcare organizations. A lack of teamwork is often identified as a primary point of vulnerability for quality and safety of care [1, 2]. Improving teamwork has therefore received top priority. There is a strong belief that effectiveness of healthcare teams can be improved by team interventions, as a wide range of studies have shown a positive effect of team interventions on performance outcomes (e.g. effectiveness, patient safety, efficiency) within diverse healthcare setting (e.g. operating theatre, intensive care unit, or nursing homes) [3-7].

In light of the promising effects of team interventions on team performance and care delivery, many scholars and practitioners evaluated numerous interventions. A decade ago (2008), we conducted a systematic review with the aim of providing an overview of interventions to improve team effectiveness [8]. This review showed a high variety of team interventions in terms of type of intervention (i.e. simulation training, crew resource management (CRM) training, interprofessional training, general team training, practical tools, and organizational interventions), type of teams (e.g. multi-, mono-, and interdisciplinary), type of healthcare setting (e.g. hospital, elderly care, mental health, and primary care), and quality of evidence [8]. From 2008 onward, the literature on team interventions rapidly evolved, which is evident from the number of literature reviews focusing on specific types of interventions. For example, in 2016, Hughes et al. [3] published a meta-analysis demonstrating that team training is associated with teamwork and organizational performance and has a strong potential for improving patient outcomes and patient health. In 2016, Murphy et al. [4] published a systematic review, which showed that simulation-based team training is an effective method to train a specific type of team (i.e. resuscitation teams) in the management of crisis scenarios and has the potential to improve team performance. In 2014, O'Dea et al. [9] showed with their meta-analysis that CRM training (a type of team intervention) has a strong effect on knowledge and behaviour in acute care settings (as a specific healthcare setting). In addition to the aforementioned reviews, a dozen additional literature reviews that focus on the relationship between (a specific type of) team interventions and team performance could be mentioned $[7,10-19]$. In sum, the extensive empirical evidence shows that team performance can be improved through diverse team interventions.

However, each of the previously mentioned literature reviews had a narrow scope, only partly answering the much broader question of how to improve team effectiveness within healthcare organizations. Some of these reviews focus on a specific team intervention, while others on a specific area of health care. For example, Tan et al. [7] presented an overview on team simulation in the operating theatre and O'Dea et al. [9] focused on CRM intervention in acute care. Other reviews only include studies with a certain design. For instance, Fung et al. [13] included only randomized controlled trials, quasi-randomized controlled trials, controlled before-after studies, or interrupted time series. Since the publication of our systematic review in 2010 [8], there has been no updated overview of the wide range of team interventions without restrictions regarding the type of team intervention, healthcare setting, type of team, or research design. Based on the number and variety of literature reviews conducted in recent years, we can state that knowledge on how to improve team effectiveness (and related outcomes) has progressed quickly, but at the same time is quite scattered. An updated systematic review covering the past decade is therefore relevant.

The purpose of this study is to answer two research questions: (1) What types of interventions to improve team effectiveness (or related outcomes) in health care have been researched empirically, for which setting, and for which outcomes (in the last decade)? (2) To what extent are these findings evidence based?

\section{Methodology \\ Search strategy}

The search strategy was developed with the assistance of a research librarian from a medical library who specializes in designing systematic reviews. The search combined keywords from four areas: (1) team (e.g. team, teamwork), (2) health care (e.g. health care, nurse, medical, doctor, paramedic), (3) interventions (e.g. programme, intervention, training, tool, checklist, team building), (4) improving team functioning (e.g. outcome, performance, function) OR a specific performance outcome (e.g. communication, competence, skill, efficiency, productivity, effectiveness, innovation, satisfaction, well-being, knowledge, attitude). This is similar to the search terms in the initial systematic review [8]. The search was conducted in the following databases: EMBASE, MEDLINE Ovid, Web of Science, Cochrane Library, PsycINFO, CINAHL EBSCO, and Google Scholar. The EMBASE version of the detailed strategy was used as the basis for the other search strategies and is provided as additional material (see Additional file 1). The searches were restricted to articles published in English in peer-reviewed journals between 2008 and July 2018. This resulted in 5763 articles. In addition, 262 articles were identified through the systematic reviews published in the last decade [3, 4, 7, 9-28]. In total, 6025 articles were screened.

\section{Inclusion and exclusion criteria}

This systematic review aims to capture the full spectrum of studies that empirically demonstrate how healthcare 
organizations could improve team effectiveness. Therefore, the following studies were excluded:

1. Studies outside the healthcare setting were excluded. Dental care was excluded. We did not restrict the review to any other healthcare setting.

2. Studies without (unique) empirical data were excluded, such as literature reviews and editorial letters. Studies were included regardless of their study design as long as empirical data was presented. Book chapters were excluded, as they are not published in peer-reviewed journals.

3. Studies were excluded that present empirical data but without an outcome measure related to team functioning and team effectiveness. For example, a study that evaluates a team training without showing its effect on team functioning (or care provision) was excluded because it does not provide evidence on how this team training affects team functioning.

4. Studies were excluded that did not include a team intervention or that included an intervention that did not primarily focus on improving team processes, which is likely to enhance team effectiveness (or other related outcomes). An example of an excluded study is a training that aims to improve technical skills such as reanimation skills within a team and sequentially improves communication (without aiming to improve communication). It is not realistic that healthcare organizations will implement this training in order to improve team communication. Interventions in order to improve collaboration between teams from different organizations were also eliminated.

5. Studies with students as the main target group. An example of an excluded study is a curriculum on teamwork for medical students as a part of the medical training, which has an effect on collaboration. This is outside the scope of our review, which focuses on how healthcare organizations are able to improve team effectiveness.

In addition, how teams were defined was not a selection criterion. Given the variety of teams in the healthcare field, we found it acceptable if studies claim that the setting consists of healthcare teams.

\section{Selection process}

Figure 1 summarizes the search and screening process according to the Preferred Reporting Items for Systematic Reviews and Meta-Analyses (PRISMA) format. A four-stage process was followed to select potential articles. We started with 6025 articles. First, each title and abstract was subjected to elimination based on the aforementioned inclusion and exclusion criteria. Two reviewers reviewed the title/abstracts independently. Disagreement between the reviewers was settled by a third reviewer. In case of doubt, it was referred to the next stage. The first stage reduced the number of hits to 639. Second, the full text articles were assessed for eligibility according to the same set of elimination criteria. After the full texts were read by two reviewers, 343 articles were excluded. In total, 297 articles were included in this review. Fourth, the included articles are

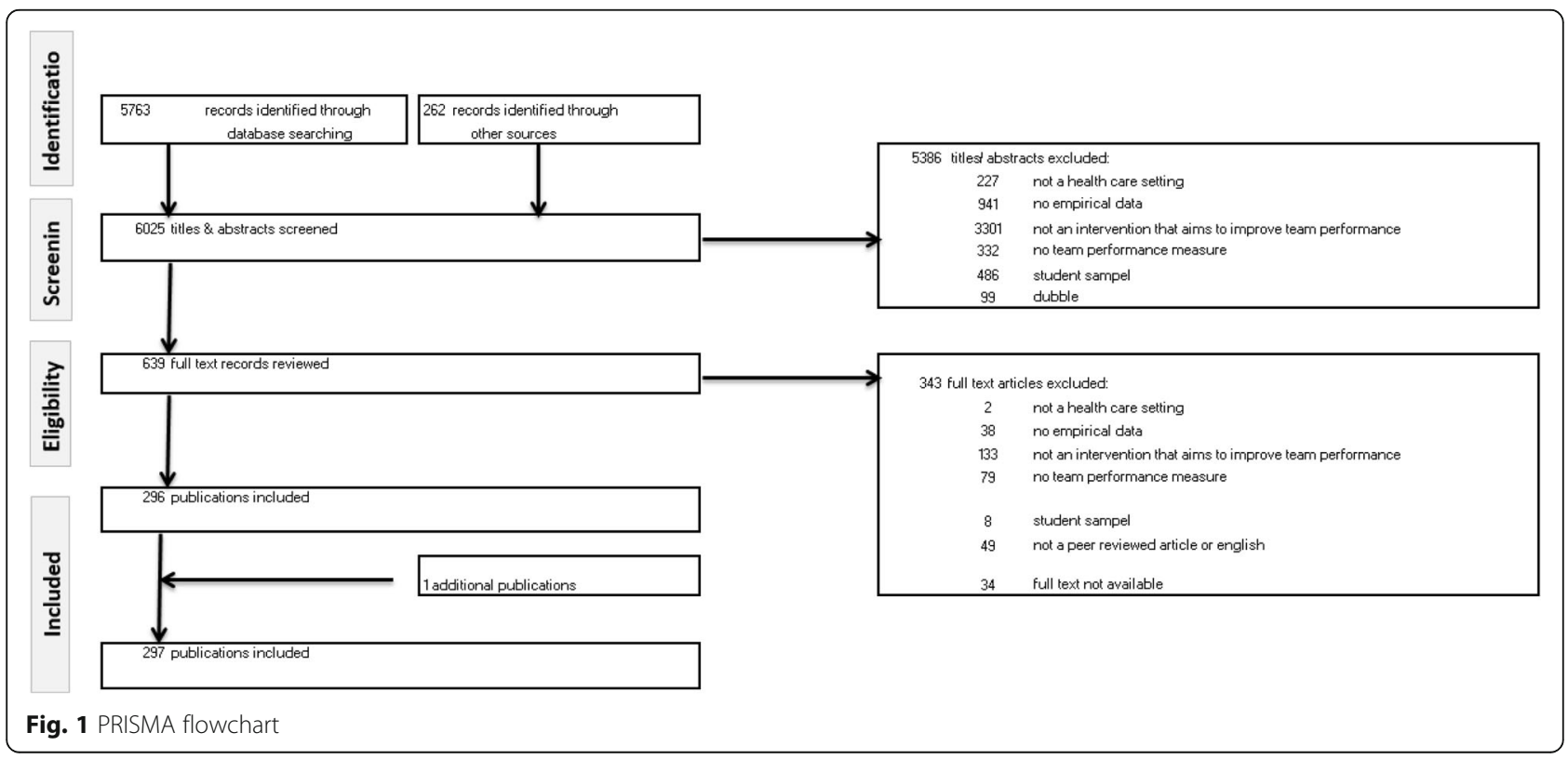


summarized in Table 1. Each article is described using the following structure:

- Type of intervention

- Setting: the setting where the intervention is introduced is described in accordance with the article, without further categorization

- Outcomes: the effect of the intervention

- Quality of evidence: the level of empirical evidence is based in the Grading of Recommendations Assessment Development, and Evaluation (GRADE) scale. GRADE distinguishes four levels of quality of evidence

A. High: future research is highly unlikely to change the confidence in the estimated effect of the intervention.

B. Moderate: future research is likely to have an important impact on the confidence in the estimated effect of the intervention and may change it.

C. Low: future research is very likely to have an important impact on the confidence in the estimated effect of the intervention and is likely to change it.

D. Very low: any estimated effect of the intervention is very uncertain.

Studies can also be upgraded or downgraded based on additional criteria. For example, a study is downgraded by one category in the event there are important inconsistencies. Detailed information is provided as additional material (see Additional file 2).

\section{Organization of results}

The categorization of our final set of 297 articles is the result of three iterations. First, 50 summarized articles were categorized using the initial categorization: team training (subcategories: CRM-based training, simulation training, interprofessional training, and team training), tools, and organizational intervention [8]. Based on this first iteration, the main three categories (i.e. training, tools, and organizational interventions) remained unchanged but the subcategorization was further developed. Training, related to the subcategory "CRM-based training", "TeamSTEPPS" was added as a subcategory. The other subcategories (i.e. simulation training, interprofessional training, and team training) remained the same. Tools, the first draft of subcategories, entailed Situation, Background, Assessment, and Recommendation (SBAR), checklists, (de)briefing, and task tools. Two subcategories of organizational intervention (i.e. programme and (re)design) were created, which was also in line with the content of this category in the original literature review. Second, 50 additional articles were categorized to test and refine the subcategories. Based on this second iteration, the subcategories were clustered, restructured and renamed, but the initial three main categorizations remained unaffected. The five subcategories of training were clustered into principle-based training, method-based training, and general team training. The tools subcategories were clustered into structuring, facilitating, and triggering tools, which also required two new subcategories: rounds and technology. Third, the remaining 197 articles were categorized to test the refined categorization. In addition, the latter categorization was peer reviewed. The third iteration resulted in three alterations. First, we created two main categories based on the two subcategories "organizational (re)design" and "programme" (of the third main categorization). Consequently, we rephrased "programme-based training" into "principle-based training". Second, the subcategories "educational intervention" and "general team training" were merged into "general team training". Consequently, we rephrased "simulation training" into "simulation-based training". Third, we repositioned the subcategories "(de)briefing" and "rounds" as structuring tools instead of facilitating tools. Consequently, we merged the subcategories "(de)briefing" and "checklists" into "(de)briefing checklists". Thereby, the subcategory "technology" became redundant.

\section{Results}

Four main categories are distinguished: training, tools, organizational (re)design, and programme. The first category, training, is divided in training that is based on specific principles and a combination of methods (i.e. CRM and Team Strategies and Tools to Enhance Performance and Patient Safety (TeamSTEPPS)), a specific training method (i.e. training with simulation as a core element), or general team training, which refers to broad team training in which a clear underlying principle or specific method is not specified. The second category, tools, are instruments that are introduced to improve teamwork by structuring (i.e. SBAR (Situation, Background, Assessment, and Recommendation), (de)briefing checklists, and rounds), facilitating (through communication technology), or triggering (through monitoring and feedback) team interaction. Structuring tools partly standardize the process of team interaction. Facilitating tools provide better opportunities for team interaction. Triggering tools provide information to incentivize team interaction. The third category, organizational (re)design, refers to (re)designing structures (through implementing pathways, redesigning schedules, introducing or redesigning roles and responsibilities) that will lead to improved team processes and functioning. The fourth category, a programme, refers to a combination of the 
Table 1 Summary of results

\begin{tabular}{|c|c|}
\hline Authors (year) & Intervention \\
\hline \multicolumn{2}{|c|}{ Principle-based training: CRM-based training } \\
\hline Allan et al. 2010 [29] & $\begin{array}{l}\text { A simulation-based in situ CRM } \\
\text { training: game play, didactics, video } \\
\text { review, hands-on high-fidelity } \\
\text { simulation-based training and video- } \\
\text { based debriefing }\end{array}$ \\
\hline Ballangrud et al. 2014 [30] & $\begin{array}{l}\text { Simulation-based CRM team } \\
\text { training: introductory theory inputs } \\
\text { on safe team performance based on } \\
\text { CRM and a team training in a } \\
\text { simulation laboratory }\end{array}$ \\
\hline Bank et al. 2014 [31] & Needs-based paediatric CRM \\
\hline
\end{tabular}
simulation training with post activity follow-up: plenary educational session, simulation and debriefing

Budin et al. 2014 [32]

Carbo et al. 2011 [33]

Catchpole et al. 2010 [34]

Clay-Williams et al. 2013 [35]

Cooper et al. 2008 [36]

France et al. 2008 [37]

Gardner et al. 2008 [38]

Gore et al. 2010 [39] classroom training of interactive discussions, and coaching in theatre
Simulation-based anaesthesia CRM training

CRM training: CRM introductory training course (i.e. lectures, case studies, and role playing) and perioperative CRM training (i.e. elearning models and toolkit consisting of CRM process checklist, briefing scripts, communication whiteboard, implementation training)

Simulation-based CRM training with debriefing

CRM training: educational seminar (i.e. lectures and role-play exercises), development and expansion of time-out briefing, educational video on briefing, posters on content

Setting

Outcome(s)

GRADE

Paediatric cardiac intensive Improvement in participants' care

perceived ability to function as a code team member and confidence in a code, likeliness to raise concerns about inappropriate management to the code leader

Intensive care

Training increases awareness of clinical practice and acknowledges the importance of structured work in teams

Paediatric emergency

medicine residents

(postgraduate year 1-5)

Improvement in the ability to be an effective team leader in general, delegating tasks appropriately, and ability to ensure closed loop communication, and identification of CRM errors

Perinatal care

Improvement in nurse and physician C perceptions of teamwork and safety climate

Inpatient internal medicine Improvement in the percentage of correct answers on a question related to key teamwork principles, reporting "would feel comfortable telling a senior clinician his/her plan was unsafe"

Surgery

More time-outs, briefings, and debriefings

(n)

Doctors, nurses and midwives

Anaesthesiology

Surgery

Obstetrics department

Reduction in annual obstetrical malpractice premiums; improvement in teamwork and communication in managing a critical obstetric event in the interval

Operating room
Improvement in knowledge, selfassessed teamwork behaviour and independently observed teamwork behaviour when classroom-only trained group was compared with control, these changes were not found in the group that received classroom followed by simulation training

No difference between the trained and untrained cohorts

Shows potential to improve team behaviour and performance 
Table 1 Summary of results (Continued)

\begin{tabular}{llll}
\hline Authors (year) & Intervention & Setting & Outcome(s) \\
\hline Haerkens et al. 2017 [40] & briefing & & \\
& $\begin{array}{l}\text { CRM training: CRM awareness } \\
\text { training (i.e. lectures and multiple } \\
\text { interactive sessions using case }\end{array}$ & Emergency department & $\begin{array}{l}\text { Improvement in teamwork climate, B } \\
\text { safety climate and stress recognition. } \\
\text { Increase in patient length of stay }\end{array}$
\end{tabular}

Haller et al. 2008 [41]

Hefner et al. 2017 [42]

Hicks et al. 2012 [43]

Hughes et al. 2014 [44]

de Korne et al. 2014 [45]

Kuy and Romero 2017 [46]

LaPoint et al. 2012 [47]

Mahramus et al. 2016 [48] studies and video footage),

implementation of tools

CRM training: video, discussion, (interactive) lectures, workshops, play roles, interactive course

CRM training: day-long retreats, during which participants underwent developed and tailored CRM safety tools and participated in role playing, development of system-wide internal monitoring processes

Crisis Resources for Emergency Workers (CREW): a simulation-based CRM curriculum: precourse learning and a full-day simulation-based exercise with debriefing

CRM adapted to Trauma Resuscitation with new cultural and process expectation: CRM course of 15 sessions

Team Resource Management (TRM) programme (based on CRM concepts): safety audits of processes and (team) activities, interactive classroom training sessions by aviation experts, a flight simulator session, and video recording of team activities with subsequent feedback

CRM training: didactics, group discussions, and simulation training

CRM training: core skills workshops Perioperative staff

Teamwork training based on CRM and TeamSTEPPS: simulations, debriefing, teamwork education

Classroom non-technical skills
Surgical service staff at a VA Hospital

Medical centre consisting of multiple hospitals and two campuses

Emergency department

Trauma resuscitation

Eye hospital safety awareness and safety-related patterns of behaviour between professions, including communication

At $\mathrm{T} 1$ participants reported improvement in all 27 areas assessed. At T2 his improvement was sustained in $85 \%$ of the areas studied. Areas with largest improvement: briefing, collaboration, nursing input, and patient safety. Areas with regression: speaking up, expressing disagreement, level of staffing, and discussing errors

Improvement in supervisor expectations, communication openness, teamwork within units, non-punitive response to error, hospital management support for safety, handoffs. No significant improvement in organizational learning, feedback communication about errors, teamwork across hospital units, number of events

Hospital

Improvement in perceptions of teamwork behaviours

Improved technical and non-

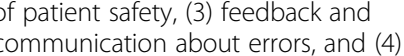

Believe that CREW could reduce errors and improve patient safety; no improvement toward team-

Improvement in accuracy of field to medical command information, medical command information to , communication of plan, role assignment, likeliness to speak up when patient safety was a concern 
Table 1 Summary of results (Continued)

\begin{tabular}{ll}
\hline Authors (year) & Intervention \\
\hline & training based on CRM: mixed di- \\
& dactic and interactive teaching (e.g. \\
& role play), follow-up feedback by \\
& trainers \\
& Multidisciplinary simulation course: \\
& CRM teaching, simulation with \\
debriefing, closing session with \\
feedback
\end{tabular}

Morgan et al. 2015a [51]

Morgan et al. 2015b [52]

Muller et al. 2009 [53]

Parsons et al. 2018 [54]

Phipps et al. 2012 [55]

Ricci et al. 2012 [56]

Robertson et al. 2009 [57]

Savage et al. 2017 [58]

Sax et al. 2009 [59]

Shea-Lewis et al. 2009 [60] of perioperative checklist
CRM-based training and improving working processes through implementing morning briefing and WHO Surgical Safety Checklist

Teamwork training course CRMbased interactive classroom teaching and on the job coaching

CRM training (i.e. psychological teaching including theoretical exercises and simulator scenarios and video-assisted debriefing) versus classic simulator training (MED)

Simulation-based CRM training: didactic presentation, series of simulation scenarios and structured debriefs

CRM-based training: didactic sessions, simulation and debriefing

CRM training: Training (i.e. didactics, case study discussions, teambuilding exercises, simulated operating room brief and debrief sessions) and CRM techniques (e.g. preoperative checklist and brief, postoperative debrief, read and initial files, feedback tools)

Obstetric Crisis Team Training: online module, training session (standardized, simulated crisis scenarios with simulator mannequin), and debriefings

CRM safety programme: CRM training (i.e. didactic seminars, role playing), systematic risk assessments, and improving work practices (i.e. checklists, huddles or structured communication and meeting tools)

Multidisciplinary obstetric providers in hospital

Paediatric surgery

Hospitals

CRM training: video, team building exercises, open forum, and development and implementation

CRM-based training: real-life examples, feedback, SBAR, team meetings, briefing, and debriefing

Operating room conducting elective orthopaedic surgery

Operating rooms

Hospital

Emergency medicine

Labour and delivery

Perioperative personnel

Outcome(s)

GRADE

technical performance: improvement

in attitudes to safety, team nontechnical performance and technical error rates

Improvement in clinical knowledge, teamwork, leadership and nontechnical skills, as well as the mutual understanding and respect between related medical and non-medical team members

Improvement in non-technical skills and WHO compliance; no significant improvement in clinical outcomes

Improvement in non-technical skills, B but also with a rise in operative glitches

Improvement in clinical and nontechnical performance after both training, but no difference between training

No significant improvement in leadership, problem solving, communication, situational awareness, teamwork, resource utilization and overall CRM skills

Improvement in patient outcomes (adverse outcomes), perceptions of patient safety including the dimensions of teamwork and communication

Wrong site surgeries and retained foreign bodies decreased, but increased after 14 months without additional training.

Improvement in attitude; perception C of individual and team performance, and overall team performance

Improvement in non-technical skills, A the use of safety tools, adherence to guidelines, safety culture (i.e. teamwork across and within units, supervisors' expectations and actions, non-punitive response to adverse events, perceptions of overall patient safety); unplanned readmissions following appendectomy declined

Increased self-initiated error reports and perceived self-empowerment

Improvement in patient outcome, patient satisfaction, employee satisfaction 
Table 1 Summary of results (Continued)

\begin{tabular}{|c|c|}
\hline Authors (year) & Intervention \\
\hline Schwartz et al. 2018 [61] & $\begin{array}{l}\text { Clinical Team Training (CTT) based } \\
\text { on CRM principles: training (e.g. } \\
\text { simulation) and implementation of } \\
\text { improvement projects (e.g. briefing, } \\
\text { huddles, checklists) }\end{array}$ \\
\hline Sculli et al. 2013 [62] & $\begin{array}{l}\text { Nursing CRM: interactive didactic } \\
\text { training curriculum, features high- } \\
\text { fidelity simulation, ongoing consult- } \\
\text { ation, improvement project, } \\
\text { refreshment }\end{array}$ \\
\hline Steinemann et al. 2011 [63] & $\begin{array}{l}\text { Crisis Team Training-based in situ } \\
\text { team training: web-based didactic, } \\
\text { simulations, and debriefing }\end{array}$ \\
\hline Stevens et al. 2012 [64] & $\begin{array}{l}\text { CRM-based educational programme } \\
\text { based on high realism acute crisis } \\
\text { simulation scenarios and interactive } \\
\text { workshop }\end{array}$ \\
\hline
\end{tabular}

Bridges et al. 2014 [70]

Brodsky et al. 2013 [71]
Suva et al. 2012 [65]

West et al. 2012 [67]

Ziesmann et al. 2013 [68]

CRM training: introductory course, interactive workshops, lecture, role play

Nursing CRM training: educational sessions, podcasts, simulation and debriefing

Nursing CRM training: didactic session, simulation, implementation of a CRM technique: sterile cockpit rule

STARTT (Standardized Trauma and Resuscitation Team Training): lectures (on CRM), discussion based on CRM principles, simulations and debriefing

Principle-based training: TeamSTEPPS

Armour Forse et al. 2011 [69] TeamSTEPPS
Educational intervention: adapted TeamSTEPPS curriculum, discussion, practicing standardized communication tools

Setting
Veterans Health
Administration facilities

Nursing units

Outcome(s)

Improvement in communication,

teamwork and situational awareness

for patient safety. Also decreased

between $\mathrm{T} 1$ and $\mathrm{T} 2$ detected.

Improvement unit climate,

teamwork, medication errors, HAPU,

glucose control, FTR events, and

care processes

Emergency department

Improvement in teamwork ratings, clinical task speed and completion rates, teamwork scores, objective parameters of speed and completeness of resuscitation

Cardiac surgery

Survey: improvement in the concept of working as a team. Interview: improvement in personal behaviours and patient care, including speaking up more readily and communicating more clearly

Operating room

Improvement in learning, knowledge regarding teamwork, safety climate, and stress recognition; improvement varies with participant specialty

General medicine telemetry unit

No significant improvement in communication openness and environmental values; RNs reported an increase in both synchronous communication and asynchronous communication with physicians whereas physicians noted a reduction in time spent in asynchronous communication

Veterans Affairs hospital on Improvement in efficiency (e.g. nursing units quicker follow-up on abnormal vital signs and blood glucose levels, rapid assessment of patients with changes in condition, and faster intervention when the condition was deteriorating) and perceived teamwork, communication, patient safety

Trauma teams

Improvement in overall CRM domains, teamwork, and safety climate

Operating room

Hospital Intermediate Care Unit serving adult medical cardiac patients

Improvement in communications, leadership first case starts, Surgical Quality Improvement Program measures, surgical morbidity and mortality, culture; not all improvement were sustained. No significant effect on PACU communication and teamwork

Improvement in awareness of teamwork and backup 
Table 1 Summary of results (Continued)

\begin{tabular}{ll}
\hline Authors (year) & Intervention \\
\hline & interactive workshop based on \\
& TeamSTEPPS \\
Bui et al. 2018 [72] & Video and live observation of \\
& TeamSTEPPS skills implementation \\
& during surgical briefs and debriefs \\
Capella et al. 2010 [73] & TeamSTEPPS (e.g. didactic session, \\
& $\begin{array}{l}\text { simulation, } 5 \text { tools: briefing, STEP } \\
\text { (situation monitoring tool), CUS } \\
\text { (mutual support tool), call outs, and } \\
\text { check backs) }\end{array}$
\end{tabular}

Castner et al. 2012 [74]

Deering et al. 2011 [75]

Figueroa et al. 2013 [76]

Gaston et al. 2016 [77]

Gupta et al. 2015 [78]

Harvey et al. 2014 [79]

Jones et al. 2013 [80]

Jones et al. 2013 [81]

Lee et al. 2017 [82]

Lisbon et al. 2016 [83]

Mahoney et al. 2012 [84]

Mayer et al. 2011 [85] (SBT) versus case study review, both
TeamSTEPPS-based simulation training: lecture (on TeamSTEPPS principles), simulation, checklist, and debriefing

Customized TeamSTEPPS training (of 2 instead of 6 h)

A selection of TeamSTEPPS tools

In situ simulation-based training incorporating TeamSTEPPS training

TeamSTEPPS (e.g. TeamSTEPPS tools, Hospitals fundamentals course)

TeamSTEPPS (e.g. essentials course) care

Setting

Operating rooms

Level I trauma centre

Hospital inpatient bedside RNs

Combat support hospital

Paediatric cardiovascular intensive care

Oncology acute patient

Academic interventional ultrasound service

Medical-surgical PCUs

Emergency department

After TeamSTEPPS, implementation of reinforcement activities regarding leadership and communication (i.e. lectures, self-paced learning programme, 1 page summary, and grand rounds on TeamSTEPPS principles)

TeamSTEPPS: brief, huddle, DESC (constructive approach for managing and resolving Conflict) and CUS script

TeamSTEPPS (variation of tools: flyers, simulations, games, and sustainment tools such as luncheon debriefing, awards)

TeamSTEPPS (e.g. fundamental

Orthopaedic surgery

Academic emergency

Psychiatric hospital

Paediatric and surgical
Outcome(s)

GRADE

teamwork, communication, situation

awareness, support, satisfaction, job fulfilment, respect

Low compliance with TeamSTEPPS skills; compliance was under video observation than under live observation

Improvement in leadership situation monitoring, mutual support, communication, and overall teamwork; decreasing the times from arrival to the CT scanner, endotracheal intubation and the operating room

Improved perceptions of leadership

Decreases in the rates of communication-related errors, medication and transfusion errors, and needles tick incidents, the rate of incidents coded communication as the primary teamwork skill that could have potentially prevented the event

Improving confidence, skills in the

role of team leaders, and

TeamSTEPPS concepts

Improvement in staff perception of teamwork and communication

Improvement in teamwork climate, C safety climate, and teamwork

Improvement in knowledge and teamwork skills in both groups; SBT group showed greater improvement in all areas except knowledge

Improvement in safety culture

Improvement of staff perception related to a culture of safety (e.g. management support for patient safety, feedback and communications about error, communication openness)

Nursing staff: improvement in leadership and communication behaviours. Surgical staff: improvement in leadership behaviours. Anaesthesia staff: no improvement in any teamwork behaviours Improvement in knowledge and improved communication attitudes; adoption of a specific behaviour, the huddle, also was observed Improvement in team foundation, functioning, performance, skills, climate, and atmosphere 
Table 1 Summary of results (Continued)

\begin{tabular}{|c|c|c|c|c|}
\hline Authors (year) & Intervention & Setting & Outcome(s) & GRADE \\
\hline & curriculum) & intensive care & $\begin{array}{l}\text { teamwork, team performance, } \\
\text { communication openness and } \\
\text { clinical outcomes (e.g. average time } \\
\text { for placing patients on } \\
\text { extracorporeal membrane } \\
\text { oxygenation, average duration of } \\
\text { adult surgery rapid response team } \\
\text { events }\end{array}$ & \\
\hline Rice et al. 2016 [86] & $\begin{array}{l}\text { Modified simulation-based Team- } \\
\text { STEPPS training }\end{array}$ & Intensive care & $\begin{array}{l}\text { Improvement in teamwork attitudes, } \\
\text { perceptions, and performance }\end{array}$ & $D$ \\
\hline Riley et al. 2011 [87] & $\begin{array}{l}\text { TeamSTEPPS didactic training (e.g. } \\
\text { webinar, video of simulated } \\
\text { scenarios) versus full TeamSTEPPS } \\
\text { training (e.g. series of in situ } \\
\text { simulation training exercises }\end{array}$ & Hospitals & $\begin{array}{l}\text { Improvement in perinatal morbidity } \\
\text { between the pre- and post- } \\
\text { intervention for hospital with simula- } \\
\text { tion programme. No significant } \\
\text { changes in safety culture }\end{array}$ & B \\
\hline
\end{tabular}

Sawyer et al. 2013 [88]

Sonesh et al. 2015 [89]

Spiva et al. 2014 [90]

Stead et al. 2009 [91]

Thomas et al. 2012 [92]

Treadwell et al. 2015 [93]

Vertino 2014 [94]

Weaver et al. 2010 [15]

Wong et al. 2016 [95]
Adapted TeamSTEPPS (lecture-based Obstetrical setting interactive programme)

Training curriculum based on TeamSTEPPS (e.g. didactic lecture, patient video vignettes, debriefing)

TeamSTEPPS (e.g. redesign meetings, SBAR, coaching)

TeamSTEPPS (e.g. master trainer course, fundamentals course, essentials course)

TeamSTEPPS (e.g. huddle, debrief, SBAR, briefing checklist)

TeamSTEPPS (e.g. formal presentation, discussion, role-play exercises embodying clinical scenarios)

TeamSTEPPS (e.g. didactic session, interactive role playing, multiple tools)

Interprofessional education course: adapted TeamSTEPPS curriculum,
Hospital

Mental health facility

Hospital

Medical home

Inpatient (VHA) hospital unit

Operating rooms

Emergency department
Improvement in teamwork skills in team structure, leadership, situation monitoring, mutual support, and communication, the odds of a nurse challenging an incorrect medication dose, and detection and correction of inadequate chest compressions

Improvement in knowledge of communication strategies, decision accuracy, and length of babies' hospital length of stay. Knowledge of other team competencies or selfreported teamwork did not significantly improve

Improvement on fall reduction and teamwork

Substantial impact on patient safety culture (i.e. frequency of event reporting, and curriculum learning), teamwork, communication, KSA score, rates of seclusion. Issues around staffing, teamwork across hospital units, and hospital management support remained unchanged

Improvement in feedback and communication about error, frequency of events reported, hospital handoff and transitions, staffing, and teamwork across the units

Improved perception of team collaboration

Positive change in staff attitudes toward team structure, leadership situation monitoring, mutual support, and communication

Improvement in quality and quantity of briefings and the use of quality teamwork behaviours during cases

Improvement in team structure, leadership, situation monitoring,

\section{C}


Table 1 Summary of results (Continued)

\begin{tabular}{|c|c|c|c|c|}
\hline Authors (year) & Intervention & Setting & Outcome(s) & GRADE \\
\hline & $\begin{array}{l}\text { simulation scenarios, and structured } \\
\text { debriefing, and wrap-up session }\end{array}$ & & $\begin{array}{l}\text { mutual support, frequency of event } \\
\text { reporting, teamwork within hospital } \\
\text { units, and hospital handoffs and } \\
\text { transitions }\end{array}$ & \\
\hline
\end{tabular}

Method-based training: Simulation-based training

AbdelFattah et al. 2018 [96]

Trauma-focus simulation training: trauma simulations with videobased debriefing

Amiel et al. 2016 [97]

Arora et al. 2014 [98]

Arora et al. 2015 [99]

Artyomenko et al. 2017 [100]

Auerbach et al. 2014 [101]

Bender et al. 2014 [102]

Bittencourt et al. 2015 [103]

Bruppacher et al. 2010 [104]

Bursiek et al. 2017 [105]
One-day simulation- based training with video-based debriefing

Full-hospital simulation across the entire patient pathway (with integration of teams in prehospital, through-hospital, and post-hospital care)

Simulation-based training for improving residents' management of post-operative complications: ward-based scenarios and debriefing intervention

Simulation training sessions for urgent conditions with debriefing

In situ interdisciplinary paediatric trauma quality improvement simulation: simulated patient care followed by debriefing

Simulation-enhanced booster session (after Neonatal Resuscitation Program): orientations session, simulation, and debriefing

In centre simulation-based training (simulation and debriefing) and in situ simulation (simulation and debriefing): comparison of actual paediatric emergencies, in-centre simulations, and in situ simulations

Training session with either highfidelity simulation-based training (i.e. orientation session, simulation, and debriefing) or an interactive seminar (i.e. audiovisual aids such as PowerPoint slides, handouts, and face-toface discussion of paper-based scenarios similar to the simulation training)

Interdisciplinary (high-fidelity)
Trauma surgery

Emergency department in trauma centre

Hospital

Surgery

Obstetrical anaesthesiologists

Tertiary care paediatric emergency department

Paediatric and Family Practice

Paediatric level 1 trauma centre

Anaesthesiology for cardiopulmonary bypass
Improvement in clinical management, leadership, communication, cooperation, professionalism and performance on trauma rotation

Improvement in teamwork, communication, patient handoff, and shock and haemorrhage control

Improvement in decision making, situational awareness, trauma care, and knowledge of hospital environment. Behavioural skills, such as teamwork and communication, did not show significant improvement

Clinically, improvement in residents' ability to recognize/respond to falling saturations, check circulatory status, continuously reassess patient, and call for help. Teamwork, improvement in residents' communication, leadership, decision-making skills, and interaction with patients (empathy, organization, and verbal and nonverbal expression)

Improvement in speed and invasive techniques, teamwork and effectiveness after the fifth session

Improvement in overall performance, teamwork, and intubation subcomponents

The intervention group demonstrated better procedura skills and teamwork behaviours. The NICU programme demonstrated better teamwork behaviours compared with non-NICU programme

Mean total TEAM scores were similar B among the 3 settings. Simulationbased training improved communication, team interaction, shared mental models, clarifying roles and responsibilities, and task management

Both groups improved, the simulation group showed significantly higher improvement on situation awareness, team working, decision making, task management, and checklist performance compared with the seminar group B 
Table 1 Summary of results (Continued)

\begin{tabular}{|c|c|}
\hline Authors (year) & Intervention \\
\hline & simulation training with debriefing \\
\hline Burton et al. 2011 [106] & $\begin{array}{l}\text { Simulation-based training: } \\
\text { simulation laboratory curriculum } \\
\text { with video-assisted debriefings }\end{array}$ \\
\hline Chung et al. 2011 [107] & $\begin{array}{l}\text { Conventional simulation-based train- } \\
\text { ing (i.e. lecture, videos, simulations, } \\
\text { and debriefing) versus a script-based } \\
\text { training }\end{array}$ \\
\hline Cooper et al. 2012 [108] & $\begin{array}{l}\text { Simulation team training: formative } \\
\text { questionnaire, team-based videoed } \\
\text { scenarios, photo elicitation, and ex- } \\
\text { pert feedback sessions }\end{array}$ \\
\hline
\end{tabular}

Ciporen et al. 2018 [109]

Crisis management simulation Neurosurgery and training: instructions, simulation, and anaesthesiology debriefing

Ellis et al. 2008 [110]

Fernando et al. 2017 [111]

Fouilloux et al. 2014 [112]

Fransen et al. 2012 [113]

Freeth et al. 2009 [114]

Frengley et al. 2011 [115]

George and Quatrara 2018 [116]

Gettman et al. 2009 [117]

Gilfoyle et al. 2017 [118]

Gum et al. 2010 [119]
High-technology training at a simulation centre versus low-tech training in local units (with and without teamwork theory)

Interprofessional simulation training with debriefing

Training based on an animal simulation model

Multiprofessional simulation team training: introduction video, simulation, and debriefing

Simulation-based interprofessional training with video-recorded debriefing

Simulation-based training: familiarization, teamwork session (presentation, video, and discussions), skills station, simulations or case-based training

Interprofessional simulation training: introduction session, simulation, and debriefing

High-Fidelity Operating Room Simulation: introduction, simulation, and video-based debriefing

Simulation-based training: lecture, group discussions, simulations, and debriefing

Interprofessional simulation training Maternity emergency with video-based debriefing in hospitals care doctors

Cardiac surgery

Delivery

Critical care

Surgical trauma burn intensive care unit

Setting

Extracorporeal membrane

oxygenation emergencies

Cardiopulmonary resuscitation in emergency

departments

Hospital nurse teams

Improvement in knowledge, confidence and competence; group debriefing session enhanced learning

No significant differences between groups in situation awareness, decision making, communication and teamwork

Midwives and obstetricians Improvement in rates of completion

for basic tasks, time to administration of magnesium sulphate, and teamwork. Training in a simulation centre and teamwork theory had no effect

Primary and secondary

Obstetric departments

mprovement in knowledge, confidence and attitudes. Qualitative data indicates improvement in clinical skills, reflective practice, leadership, teamwork and communication skills

Improvement in management of the adverse events and time spend per certain events

Improvement in teamwork performance and use of the predefined obstetric procedures

Improvement in knowledge and understanding of interprofessional team working, especially communication and leadership in obstetric crisis situations

Orology, operating room

Improvement in overall teamwork, leadership, team coordination, verbalizing situational information, clinical management; no difference between simulation-based learning and case-based learning

Improvement in perceptions of teamwork and knowledge

Improvement in teamwork, communication, laparoscopic skills, and team performance

Improvement in clinical performance and clinical teamwork (role responsibility, communication, situational awareness and decision making)

Ability for collaboration in team building (i.e. personal Role 
Table 1 Summary of results (Continued)

Authors (year) Intervention

Hamilton et al. 2012 [120]

Hoang et al. 2016 [121]

James et al. 2016 [122]

Kalisch et al. 2015 [123]

Khobrani et al. 2018 [124]

Kilday et al. 2012 [125]

Kirschbaum et al. 2012 [126]

Koutantji et al. 2008 [127]

Kumar et al. 2018 [128]

Larkin et al. 2010 [129]

Lavelle et al. 2018 [130]

Lavelle et al. 2017 [131]
High-fidelity simulated trauma resuscitation with video-assisted debriefing

Training course: classroom didactic sessions and hand-on simulation sessions

Simulation-based interprofessional team training: simulation followed by debriefing and performance feedback

Virtual simulation training with introduction session

Boot camp curriculum with highfidelity paediatric simulations with debriefing

Team intervention: didactic curriculum with skill lab practice sessions, simulations, debriefing

Multidisciplinary team training: assessments, high-fidelity simulation sessions, and debriefing

Simulations with debriefing and in between an interactive workshop on briefing, check-listing methods and protocol

Simulation-based Practical Obstetric Multi-Professional Training (PROMPT): interactive lectures, scenarios based drills, debriefing

Simulation-Based curriculum: video demonstrations, triggers, and simulated scenarios

Multidisciplinary simulation-based training designed to address Medical Emergencies in Obstetrics: lecture, orientation session, simulation, debriefing, didactic teaching

In situ, simulation training: introduction, simulation, and debriefing
Setting

Surgery

(U.S. Navy Fleet) surgery

Oncology

Medical-surgical patient care unit

(Paediatric) emergency medicine

Hospitals

Obstetricians and anaesthesiologists

Surgery

Obstetric care in hospitals Obstetic care in hospitals

Improvement in clinical and nontechnical skills highlighting principles of teamwork, communication, leadership and prioritization in an emergency situation. No significant change in clinical outcomes

Surgery

Improvement in empathic communication. Higher levels of stress. No significant improvement in teamwork attitudes

Healthcare staff across organizations

Improvement in clinical skills and non-technical skills including teamwork, communication and leadership skills

Psychiatric triage wards
Improvement in knowledge, confidence, and attitudes toward managing medical deterioration. Based on reflection: improved confidence in managing medical deterioration, better understanding of effective communication, improved self-reflection and team working, and an increased sense of responsibility for patients' physical health. Incident reporting increased by $33 \%$ 
Table 1 Summary of results (Continued)

\begin{tabular}{ll}
\hline Authors (year) & Intervention \\
\hline $\begin{array}{l}\text { simulation-based team training with } \\
\text { debriefing }\end{array}$
\end{tabular}

Lorello et al. 2016 [133]

Mager et al. 2012 [134]

Maxson et al. 2011 [135]

McLaughlin et al. 2011 [136]

Meurling et al. 2013 [137]

Miller et al. 2012 [138]

van der Nelson et al. 2014 [139]

Nicksa et al. 2015 [140]

Niell et al. 2015 [141]

Oseni et al. 2017 [142]

Paige et al. 2009 [143]

Paltved et al. 2017 [144]

Pascual et al. 2011 [145]

Patterson et al. 2013a [146]
Mental practice training (versus ATLS Trauma resuscitation training) and simulation with debriefing

Expanded Learning and Dedication to Elders in the Region (ELDER): simulated patient scenarios using mid-fidelity human patient simulators and debriefing

Interdisciplinary simulation team training with high-fidelity simulation scenarios, pre- and debriefing session

Intensive trauma team training course (ITTC): didactic lectures, case studies, and clinical simulations

Simulation-based team training: interactive seminars, simulation with debriefing

In situ trauma simulation programme: didactic session, simulation, and debriefing

Multidisciplinary simulation training with team debriefing (with emphasizes on using clinical tools)

Simulation of high-risk clinical scenarios followed by debriefings with real-time feedback

Simulation-based training: didactic instruction, simulation, and debriefing

Training: video-based feedback and low-fidelity simulation

Repetitive training using high-fidelity Operating room simulation: Module 1 targeted teamwork competencies and Module 2 included a pre-operative briefing strategy

In situ simulation: information, simulation, and debriefing

Human patient simulation training: introduction, simulation, and videobased debriefing

Multidisciplinary in situ simulations

Military healthcare

personnel

Intensive care

Surgery surgery

Radiology settings)

Intensive care
Long-term care facilities and home care agency

Inpatient surgical ward

General surgery, vascular surgery, and cardiothoracic

Research unit clinics and hospital (in low resource

Outcome(s)

GRADE

with technical performance but not

with non-technical performance; an-

aesthesia resident training level did

correlate with non-technical

performance

Improvement in teamwork

behaviour, compared to traditional

simulation-based trauma instruction

Encouraging communication and teamwork

Improvement in collaboration

C

between nurses and physicians and

patient care decision making

process

Creates self-reported confidence

Improvement in self-efficacy. Improvement in nurse assistants' perceived quality of collaboration and communication with physician specialists, teamwork climate, safety climate (also for nurses) and working conditions

Improvement in teamwork and communication, this effect was not sustained after the programme was stopped

Improvement in safety culture, teamwork climate; deterioration in perceptions of hospital management and adequacy of staffing levels

Improvement in communication,

leadership, teamwork, and procedural ability. No significant improvement in decision making, situation awareness, and skills

Improvement in their ability to manage an anaphylactoid reaction, their ability to work in a team, and knowledge

Improvement in clinical knowledge, confidence and quality of teamwork (leadership, teamwork and task management)

Improvement in the effectiveness of $\mathrm{C}$ promoting attitudinal change toward team-based competencies

Emergency department

Improvement in teamwork climate and safety climate

Improvement in leadership, teamwork, and self-confidence skills in managing medical emergencies

Ability to identify latent safety 
Table 1 Summary of results (Continued)

\begin{tabular}{ll}
\hline Authors (year) & Intervention \\
\hline Patterson et al. 2013b [147] & Simulation-based training: \\
& $\begin{array}{l}\text { introduction (lectures, videotapes of } \\
\text { simulated resuscitations and case }\end{array}$ \\
& studies), simulation, and video- \\
& assisted debriefing \\
Pennington et al. 2018 [148] & $\begin{array}{l}\text { Long distance, remote simulation } \\
\text { training with Checklist for Early }\end{array}$ \\
& Recognition and Treatment of Acute \\
& Ilness (CERTAIN) \\
& \\
Rao et al. 2016 [149] & Simulation team tasks: presentation, \\
& live-demonstration, and simulations \\
& \\
Reynolds et al. 2011 [150] & Multidisciplinary simulation-based \\
& team training: introduction, presen- \\
tation, simulation, and debriefing
\end{tabular}

Roberts et al. 2014 [151]

Rubio-Gurung et al. 2014 [152]

Sandahl et al. 2013 [153]

Shoushtarian et al. 2014 [154]

Siassakos et al. 2011 [155]

Siassakos et al. 2011 [156]

Silberman et al. 2018 [157]

Stewart-Parker et al. 2017 [158]

Stocker et al. 2012 [159]

Sudikoff et al. 2009 [160] programme (SPRinT) with debriefing

Setting
department
Paediatric emergency
department

Interdisciplinary teams in emergency situations

Operating room

Obstetrical emergencies

Team communication, leadership and team behaviour training: didactic presentations, simulation, and debriefing

In situ simulation training: briefing, simulation, and debriefing

Simulation team training: lectures, simulation, and debriefing

Practical Obstetric Multi-Professional Training (PROMPT): lectures, scenario-based simulation training

Interprofessional training programme: updates on evidencebased guidelines and simple practical means of implementing them, high-fidelity simulation

Multiprofessional simulation training

High-fidelity human simulation training: briefing, simulation, and debriefing

Simulation-based S-TEAMS course: lectures, case studies, interactive teamwork exercises, simulated scenarios, debriefing

Multidisciplinary in situ simulation

High-fidelity medical simulation: didactic teaching, hands-on skills

Outcome(s)

GRADE

threats, but changes in non-

technical skills

Sustained improvement in knowledge of and attitudes toward communication and teamwork behaviours

Improvement in global team performance: "team's ability to complete tasks in a timely manner" and in the "team leader's communication to the team"

Improvement in mean non-technical D skills and concomitant increase in technical skills

Improvement in knowledge, dealing C with teamwork related issues, and (technical) skills (particularly relevant for obstetric nurses and for those who witness all trained obstetrical emergencies)

Emergency department (ad Changed teamwork and hoc emergency teams) communication behaviour

Delivery room

Intensive care

Maternity

Maternity unit

Intensive care

Operating room

Paediatric intensive care

Improvement in the technical skills and teamwork

Increased awareness of the importance of effective communication for patient safety, created a need to talk, led to reflection meetings

Improvement in Safety Attitude (teamwork, safety and perception of management) and clinical measures (Apgar 1, cord lactates and average length of baby's stay in hospital)

Positive safety culture, teamwork climate, and job satisfaction. Perceptions of high workload and insufficient staffing levels were the most prominent negative observations

Reduction in median diagnosisdelivery interval (as indicator of teamwork)

Facilitates teamwork, collaboration, and self-efficacy for ICU clinical practice

Increase in confidence for speaking up in difficult situations, feeling the S-TEAMS had prevented participants from making errors, improved patient safety and team working

Impact on non-technical skills (team- C work, communication, confidence) and overall practice; less impact is perceived in technical skills

Paediatric emergency care Improved performance and teamwork skills; reduction in harmful

C

C

D

.


Table 1 Summary of results (Continued)

\begin{tabular}{ll}
\hline Authors (year) & Intervention \\
\hline Thomas et al. 2010 [161] & $\begin{array}{l}\text { stations, case simulation, video- } \\
\text { enhanced debriefing (with and with- } \\
\text { out supplemental education) }\end{array}$ \\
$\begin{array}{l}\text { Teamwork training: information } \\
\text { session with examples and SBAR } \\
\text { model, video clips, role playing, } \\
\text { simulation, debriefing }\end{array}$ \\
Weller et al. 2016 [162] & $\begin{array}{l}\text { Multidisciplinary Operating Room } \\
\text { Simulation (MORSim) intervention: } \\
\text { simulation, debriefing, and } \\
\text { discussion }\end{array}$
\end{tabular}

Willaert et al. 2010 [163]

Yang et al. 2017 [164]

General team training

Acai et al. 2016 [165]

Agarwal et al. 2008 [166]

Amaya-Anas et al. 2015 [167]

Barrett et al. 2009 [168]

Bleakley et al. 2012 [169]

Blegen et al. 2010 [170]

Brajtman et al. 2009 [171]
Patient-specific virtual reality (VR) simulation

Simulation-based interprofessional education course: preparation course, simulation, benchmarking, elearning

Educational creative professional development workshop: various interactive team building games, activities rooted in the dramatic arts, creative printmaking session, debriefing sessions

McMaster Interprofessional Mentorship and Evaluation (MIME) programme to increase interprofessional interactions, learn more about the roles of other healthcare professionals and improve work-life satisfaction through intentional conversations at mutually agreed times

Team training: workshops, virtual modules, time-out and checklist training, and institutional actions

Intervention on lateral violence and team building: interactive groups sessions and skill-building sessions

Complex education intervention: data-driven iterative education in human factors, establishing a local, reactive close call incident reporting system, and developing team selfreview (briefing and debriefing)

Multidisciplinary teamwork and communication training: presentations, videos, role playing, and facilitated discussion

Interprofessional educational intervention: interactive sessions consisting of a case study, discussions and presentation

\section{Setting}

Outcome(s)

GRADE

actions

Paediatric

Improvement in frequent teamwork behaviours, workload management and time to complete the resuscitation

Operating room

Improvement in communication, culture and collaboration. But difficulties with uninterested colleagues, limited team orientation, communication hierarchies, insufficient numbers of staff exposed to MORSim and failure to prioritize time for team information sharing

Improvement in sense of teamwork, C communication, and patient safety; procedure time took longer in reality

Medical centre

Improvement in interprofessional collaboration attitude, self-reflection, workplace transfer and practice of the learnt skills

Mental health and social

Positive impact on teams with low team cohesion prior to the intervention. Helps staff to bond, communicate, get to know each other better and accept each other's mistakes

Interprofessional family health teams

No significant improvement in the QWL Survey, but participant feedback from closing workshop focus groups and evaluations was positive

Operating rooms and obstetrics suites

Acute care hospital

Operating room

Two or more points of improvement in the average OTAS-S scores in every phase, behaviours and sub-teams

Improvement in group cohesion and the RN-RN interaction

Improvement in teamwork climate and reduction in stress recognition. No significant improvement in job satisfaction, perception of management, working conditions, safety climate

Inpatient medical units Improvement in supervisor manager B expectations, organizational learning, communication openness, hospital handoffs and transitions, and nonpunitive response to error

Palliative care Improvement in leadership, cohesion, communication, coordination and conflict domains

\section{B}

C 
Table 1 Summary of results (Continued)

\begin{tabular}{|c|c|}
\hline Authors (year) & Intervention \\
\hline Brajtman et al. 2012 [172] & $\begin{array}{l}\text { Interprofessional educational } \\
\text { intervention: self-learning module } \\
\text { (SLM) on end-of-life delirium and in- } \\
\text { terprofessional teamwork, team ob- } \\
\text { jective structured clinical encounter } \\
\text { (e.g. simulation team discussion and } \\
\text { debriefing), and a didactic "theory } \\
\text { burst" }\end{array}$ \\
\hline Brandler et al. 2014 [173] & $\begin{array}{l}\text { Team-based learning sessions: } \\
\text { preparation reading, tests, and } \\
\text { application-oriented activities }\end{array}$ \\
\hline Chan et al. 2010 [174] & $\begin{array}{l}\text { Intervention: educational workshop } \\
\text { (e.g. case study using role play) and } \\
\text { structured facilitation using specially } \\
\text { designed materials }\end{array}$ \\
\hline
\end{tabular}

Christiansen et al. 2017 [175]

Chiocchio et al. 2015 [176]

Cohen et al. 2016 [177]

Cole et al. 2017 [178]

Eklöf and Ahlborg 2016 [179]

Ellis and Kell 2014 [180]

Ericson-Lidman and Strandberg 2013 [181]

Fallowfield et al. 2014 [182]

Fernandez et al. 2013 [183] ecture) and team building and resiliency session (e.g. simulation game, rounds)

Workshops integrating project management and collaboration: active, learner-centred, practice oriented strategies, feedback, and small group discussions

Allied Team Training for Parkinson (ATTP): interprofessional education training on best practices and teambased care

Elective rotation of operating room management and leadership training: curriculum consisting of leadership and team training articles, crisis management text, and daily debriefings rounds using standardized flashcards, group discussions

Training: theory, group exercises, presentations

Intervention to constructively deal with their troubled conscience related to perceptions of deficient teamwork: assist care providers in extending their understanding of the difficult situation and find solutions to the problem through participatory action research

Communication skills training: workshop (e.g. presentations, exercises, discussion, role play)

Computer-based educational

$\begin{array}{lll}\text { Setting } & \text { Outcome(s) } & \text { GRADE } \\ \begin{array}{ll}\text { Long-term care facility and } \\ \text { hospice }\end{array} & \begin{array}{l}\text { Improvement in knowledge and } \\ \text { perceptions of IP competence, but } \\ \text { does depend on the presences of } \\ \text { the module }\end{array} & \text { D }\end{array}$

Pathology

Able to solve complex problems D and work through difficult scenarios in a team setting

Primary care

Improvement in patient participation, empowerment in the care process, communication and collaboration

Burn centre

Contributed to perceived unit cohesion and increasing satisfaction and morale medicine, nursing,

occupational, physical and music therapies)

Anaesthesiology

Dialogue training: multiple dialogue Hospital intervention: computer-based training module (e.g. presentations, clinical examples, simulation-based assessment) or a placebo training module
Paediatric ward

Elderly care

Breast cancer teams

Emergency care (and medical students) mprovement in satisfaction, perceptions of utility, self-efficacy for project-specific task work, teamwork, goal clarity, coordination, functional performance of projects

Improvement in self-perceived, objective knowledge, understanding role of other disciplines, attitudes toward healthcare teams, and the attitudes toward value of teams

Improvement in teamwork, task management and situational awareness

Improvement in participative safety

(i.e. information sharing, mutual influence and sense of having a common task) and social support from managers. Qualitative data shows a positive tendency toward trust/openness

Improvement in team cohesiveness, effectivity, and patient care

Support care providers to understand, handle and take measures against deficient teamwork. Using troubled conscience as a driving force can increase the opportunities to improve quality of care

Improvement in awareness and clarity about the trial(s) discussed during the training

Improvement in teamwork and patient care 
Table 1 Summary of results (Continued)

\begin{tabular}{|c|c|}
\hline Authors (year) & Intervention \\
\hline Gibon et al. 2013 [184] & $\begin{array}{l}\text { Patient-oriented communication } \\
\text { skills training module (e.g. } \\
\text { information, role play) and team- } \\
\text { resource oriented communication } \\
\text { skills training module (e.g. informa- } \\
\text { tion, role play) }\end{array}$ \\
\hline Gillespie et al. 2017 [185] & $\begin{array}{l}\text { Team training programme } \\
\text { (TEAMANATOMY): 1-h DVD (i.e. indi- } \\
\text { vidual and shared situational aware- } \\
\text { ness theory, filmed simulation pre- } \\
\text { operative patient sign-in, and filmed } \\
\text { simulation of time-out procedure) }\end{array}$ \\
\hline
\end{tabular}

Gillespie et al. 2017 [186]

Halverson et al. 2009 [187]

Howe et al. 2018 [188]

Kelm et al. 2018 [189]

Khanna et al. 2017 [190]

Körner et al. 2017 [191]

Lavoie-Tremblay et al. 2017 [192]

Lee et al. 2012 [193]
Team training programme (TEAMANATOMY): 1-h DVD (i.e. individual and shared situational awareness theory, filmed simulation preoperative patient sign-in, and filmed simulation of time-out procedure)

Team training: classroom curriculum, Operating room intraoperative coaching on teamrelated behaviours, and follow-up feedback sessions

Rural interdisciplinary team training programme: didactic mini-lectures, interactive case studies discussions, video presentations, role play demonstrations and the development of an action plan

Mindfulness meditation training using a meditation device and smartphone application at home (e.g. education, demonstration, and practice in using device, one-page summary)

Training and refresher courses on the principles of the patient-centred care medical homes: participating patient-centred medical home received coaching, learning collaborative for improving teamwork, embedded care manager

Team coaching: identification of the expectations for team coaching (need-specific), definition of the coaching goals (task-related), development of the solution (solution-focused), maintenance of the solution (systemic)

Transforming Care at the Bedside (TCAB) programme: learning modules combined with hands-on learning

Communication and Patient Safety (CASP) training: practical exercises, video clips, small group discussion

Operating room

\begin{tabular}{lll} 
Setting & Outcome(s) & GRADE \\
\hline Radiotherapy & $\begin{array}{l}\text { Improvement in team members' } \\
\text { communication skills and their self- } \\
\text { efficacy to communicate }\end{array}$ & B
\end{tabular}

Operating room

Improvement in non-technical skills (communication and interactions, situational awareness, team skills, leadership and management skills and decision making). Most significant improvement observed in surgeons. Improved use of the surgical safety checklist

Improvement in non-technical skills (communication and interactions, situational awareness, team skills, leadership and management skills and decision making) and the use of the surgical safety checklist. No improvement in perceived teamwork. No significant increase in perceived safety climate

Improvement in perception of teamwork

Veteran affairs primary care Improvement in teamwork

Pulmonary and critical medicine physicians and ICU

Primary care

Rehabilitation teams

Multhospital academic health science centre

Emergency, outpatients, maternity, and special care nursery
Improvement in teamwork, task management, and overall performance

Change in how participants responded to work-related stress, including stress in real-code situations

No significant difference in perceptions of teamwork

Improvement in team organization, willingness to accept responsibility and knowledge integration according to staff. No significant improvement in internal participation, team leadership, and cohesion

Improvement in patient satisfaction focus, overall perceived team effectiveness, perceived team skill, perceived participation and goal agreement, perceived organizational support. No significant improvement in patient experience

Changes in behaviour at individual, $C$ team, and facility levels

\section{C}


Table 1 Summary of results (Continued)

\begin{tabular}{ll}
\hline Authors (year) & Intervention \\
\hline Ling et al. 2016 [194] & and other learning techniques \\
& BASIC (Basic Assessment and \\
& Support in Intensive Care) Patient \\
& Safety Course: blended learning \\
& course with flipped classroom \\
& approach (e.g. lectures, formative \\
& assessment, interactive sessions)
\end{tabular}

Lundén et al. 2017 [195]

Drama Workshop (warm-up activities, improvizations and Forum Theatre, reflective discussions) as a learning medium

Mager et al. 2014 [196]

Magrane et al. 2010 [197]

Nancarrow et al. 2015 [198]

Prewett et al. 2013 [199]

Stephens et al. 2016 [200]

Webb et al. 2010 [201]

Tools: Structuring teamwork: SBAR

Beckett et al. 2009 [202]

Clark et al. 2009 [203]

Costa and Lusk 2017 [204]

Donahue et al. 2011 [205]
Interprofessional training course: workshops, simulated a structured debriefing technique, facilitated discussion, and sustainability strategy

Emotional intelligence coaching: homework assignments, coaching sessions, goal setting

SBAR Collaborative Communication Education (e.g. didactic content, role play, and an original DVD

demonstrating traditional and SBAR communication)

PACT (Patient assessment, Assertivecommunication, Continuum of care, Teamwork with trust) Project, aimed at improving communication between hospital staff at handover: 2 communication tools based on SBAR: Handover prompt card and reporting template

SBAR educational session

EMPOWER project: an interdisciplinary leadership-driven
Setting

Outcome(s)

GRADE

Intensive care

Improvement in teamwork within hospital units and hospital management support for patient safety, but decreased in the frequency of reporting mistakes

Radiographers and registered nurses

Enables participants to understand each other's priorities better and specialized in areas such as find the best way to co-operate radiography, operating room and anaesthesia

Long-term and home care

Quantitatively: no statistical improvement; qualitatively: better understanding of other provider roles

Academic health centres

Improvement in team skills (clarifying team charge, exploring team purpose, and evaluating team process)and institutional team performance

Community based rehabilitation or community rehabilitation servicesproviding transitional care for older people

Empowers to understand and value their own, and others' roles and responsibilities within the team; identify barriers to effective team work, and develop and implement appropriate solutions to these

Trauma resuscitation teams Improvement of behavioural choices for teamwork in the trauma room. More effective responses to teamwork issues, but no affect in case of already a positive attitudes toward teamwork

Perioperative practitioners

Improvement in team behaviours (communication, coordination cooperation and backup, leadership, situational awareness); recognizing different perspectives and expectations within the team; briefing and debriefing

Family medicine

Decline in teamwork rating and no improvement on competences

Hospital paediatrics/ perinatal services department

Improvement in communication, collaboration, satisfaction, and patient safety outcomes

Private hospital

improvement in communication, handover, and confidence in communicating with doctors

Behaviour health clinicians in correctional facilities

Marginal improvement in communication and team structure

Hospital

Improvement in communication from paraprofessional staff to

\section{C}

D

C

C

D

\section{D}$$
\text { Hospital }
$$ 
Table 1 Summary of results (Continued)

\begin{tabular}{|c|c|c|}
\hline Authors (year) & Intervention & Setting \\
\hline & $\begin{array}{l}\text { communication programme (Edu- } \\
\text { cating and Mentoring Paraprofes- } \\
\text { sionals On Ways to Enhance } \\
\text { Reporting) using SBAR }\end{array}$ & \\
\hline Martin et al. 2015 [206] & $\begin{array}{l}\text { Huddles structured with SBAR with } \\
\text { an educational session }\end{array}$ & $\begin{array}{l}\text { Paediatric emergency } \\
\text { department }\end{array}$ \\
\hline Randmaa et al. 2014 [207] & $\begin{array}{l}\text { SBAR and implementation strategies } \\
\text { (e.g. modified SBAR card, in-house } \\
\text { training course, information material } \\
\text { and observation) }\end{array}$ & Anaesthetic clinics \\
\hline Renz et al. 2013 [208] & SBAR protocol and training & Nursing homes \\
\hline
\end{tabular}

Rice et al. 2010 [209]

Sculli et al. 2015 [210]

Weller et al. 2014 [212]

Boet et al. 2011 [245]

Boet et al. 2013 [246]

Interprofessional intervention: semiscripted four-step process during all patient-related interactions (i.e. name, role, issue, and feedback) Chain of command

Tools: Structuring teamwork: (De)briefing checklist
Böhmer et al. 2012 [214]

Böhmer et al. 2013 [215]

Berenholtz et al. 2009 [244]

Bliss et al. 2012 [213]
Standardized one-page briefing and debriefing tool

Comprehensive surgical safety checklist (using pre-operative briefing and post-operative debriefing checklists) and a structured team training curriculum

Modified perioperative surgical safety checklist

Perioperative safety checklists
Effective Followership Algorithm: 3Ws (what I see; what I'm concerned about; what I want), 4Step Assertive Tool, Engage team,

SBAR Collaborative Communication Education: educational session, casebased discussion, video demonstration on traditional and SBAR communication

Video-intervention teaching SNAPPI tool: Stop the team; Notify of the patient's status; Assessment of the situation; Plan what to do; Priorities for actions; and Invite ideas

General internal medicine

Paediatric and adult operating rooms

Obstetrics department

Anaesthesiology

Operating room

Surgery

Operating room

Anaesthesiology and traumatology

Hospital

Self-debriefing versus instructor debriefing

Interprofessional within-team debriefing compared to an

Operating room
Outcome(s)

GRADE

professional staff, no significant

changes in rapid events reports

Improvement in teamwork,

communication, and nursing

satisfaction

Improvement in between-group communication accuracy, safety climate, the proportion of incident reports due to communication errors

Mixed results regarding the nurse satisfaction with nurse-medical provider communication

No changes in communication and collaboration between health professionals

Improvement in safety culture, teamwork, team performance

Improvement in teamwork climate, safety climate, job satisfaction, and working conditions

Improvement in SNAPPI score, number of diagnostic options, information sharing. No significant improvement in information probe sharing and medical management (in intervention group)

Improvement in interdisciplinary communication and teamwork

Decrease in 30-day morbidity. Cases B with safety-compromising events (e.g. inadequate communication, decision making), had higher rates of 30-day morbidity

Improvement in interprofessional coordination and communication

Improvement in verification of written consent for surgery, clear marking of the surgical site, time management, better informed about the patients, the planned operation, and the assignment of tasks during surgery in both short and long terms. Decrease in communication over longer time periods.

Improvement in situational awareness, teamwork, decision making, task management, total non-technical skills, regardless of the type of debriefing received

Improvement in team performance regardless of the type of debriefing. 
Table 1 Summary of results (Continued)

\begin{tabular}{|c|c|c|c|c|}
\hline Authors (year) & Intervention & Setting & Outcome(s) & GRADE \\
\hline & instructor-led debriefing & & $\begin{array}{l}\text { No significant difference in the } \\
\text { degree of improvement between } \\
\text { within-team debriefing and } \\
\text { instructor-led debriefing }\end{array}$ & \\
\hline Cabral et al. 2016 [216] & $\begin{array}{l}\text { Standardized, comprehensive time- } \\
\text { out and a briefing/debriefing } \\
\text { process using surgical safety } \\
\text { checklist }\end{array}$ & Surgery & $\begin{array}{l}\text { Improvement of nurses' perception } \\
\text { of communication. No significant } \\
\text { improvement of surgeons and } \\
\text { technologists perception of } \\
\text { communication }\end{array}$ & C \\
\hline Calland et al. 2011 [220] & $\begin{array}{l}\text { Surgical safety checklists } \\
\text { (intervention group included a basic } \\
\text { team training using a pre-procedural } \\
\text { checklist) }\end{array}$ & Surgery & $\begin{array}{l}\text { Improvement in team behaviour, } \\
\text { defined as discrete, objective, } \\
\text { observable shared communication } \\
\text { behaviours; more likely to involve } \\
\text { positive safety-related team } \\
\text { behaviours such as case } \\
\text { presentations, explicit discussions of } \\
\text { roles and responsibilities, } \\
\text { contingency planning, equipment } \\
\text { checks, and post case debriefings; } \\
\text { no significant differences in } \\
\text { situational awareness }\end{array}$ & A \\
\hline Dabholkar et al. 2018 [218] & Customized surgical safety checklist & Surgery & $\begin{array}{l}\text { Improvement in verification of } \\
\text { patient's identity, awareness of } \\
\text { operating team members' names } \\
\text { and roles, practice of displaying } \\
\text { radiological investigation during } \\
\text { surgery, pre-check of equipment } \\
\text { and communication }\end{array}$ & B \\
\hline Dubois et al. 2017 [219] & $\begin{array}{l}\text { Person-centred endoscopy safety } \\
\text { checklist (introduces during } \\
\text { seminars and training) }\end{array}$ & Endoscopy unit & $\begin{array}{l}\text { Improvement in quality of } \\
\text { collaboration with nurses and } \\
\text { perception. No differences in } \\
\text { teamwork }\end{array}$ & $\mathrm{D}$ \\
\hline Einav et al. 2010 [247] & $\begin{array}{l}\text { Pre-operative team briefings } \\
\text { (briefing protocol and poster) }\end{array}$ & Operating room & $\begin{array}{l}25 \% \text { reduction in the number of } \\
\text { non-routine events when briefing } \\
\text { was conducted and a significant } \\
\text { increase in the number of surgeries } \\
\text { in which no non-routine event was } \\
\text { observed. Team members evaluated } \\
\text { the briefing as most valuable for } \\
\text { their own work, the teamwork, and } \\
\text { patient safety }\end{array}$ & C \\
\hline Erestam et al. 2017 [220] & Revised surgical safety checklist & Operating room & $\begin{array}{l}\text { No significant change in teamwork } \\
\text { climate. Lack of adherence to the } \\
\text { checklist was detected }\end{array}$ & C \\
\hline Everett et al. 2017 [221] & Critical event checklists & Surgical daytime facility & $\begin{array}{l}\text { No improvement in medical } \\
\text { management or teamwork (during } \\
\text { simulation) }\end{array}$ & C \\
\hline Gleicher et al. 2017 [248] & $\begin{array}{l}\text { Standardized handover protocol } \\
\text { consisting of a handover content } \\
\text { checklist and a "sterile cockpit" time- } \\
\text { out }\end{array}$ & $\begin{array}{l}\text { Cardiovascular intensive } \\
\text { care }\end{array}$ & $\begin{array}{l}\text { Improvement in teamwork, content } \\
\text { received and patient care planning }\end{array}$ & C \\
\hline Gordon et al. 2014 [222] & Pre-procedure checklist & $\begin{array}{l}\text { Cardiac catheterization } \\
\text { laboratory }\end{array}$ & $\begin{array}{l}\text { No improvement in complication } \\
\text { rates, overall team and safety } \\
\text { attitudes }\end{array}$ & C \\
\hline Hardy et al. 2018 [223] & Malignant hyperthermia checklist & Anaesthesiology & $\begin{array}{l}\text { Improvement in non-technical skills } \\
\text { in the experiment group. Higher } \\
\text { self-reported stress in the } \\
\text { experiment group }\end{array}$ & C \\
\hline Haugen et al. 2013 [224] & Surgical safety checklist & Operating room & $\begin{array}{l}\text { Improvement in frequency of events } \\
\text { reported and adequate staffing. No } \\
\text { significant improvement in patient } \\
\text { safety, teamwork within units, }\end{array}$ & B \\
\hline
\end{tabular}


Table 1 Summary of results (Continued)

\begin{tabular}{|c|c|c|}
\hline Authors (year) & Intervention & Setting \\
\hline Haynes et al. 2011 [225] & $\begin{array}{l}\text { Checklist-based surgical safety } \\
\text { intervention }\end{array}$ & Operating rooms \\
\hline Helmiö et al. 2011 [226] & Surgical safety checklist & Operating room \\
\hline
\end{tabular}

Howe et al. 2014 [249]

Jing and Honey 2016 [227]

Kawano et al. 2014 [228]

Kearns et al. 2011 [229]

Kherad et al. 2018 [230]

Khoshbin et al. 2009 [250]

Lepanluoma et al. 2014 [231]

Lingard et al. 2008 [251]

Low et al. 2013 [232]

McLaughlin et al. 2014 [252]
Long-term care team talk programme involved regularly scheduled 5-min debriefing sessions at the end of the day shift led by a rotating schedule of certified nurse

Robotic-assisted laparoscopic radical prostatectomy checklist

Surgical safety checklist

Modified surgical safety checklist

Endoscopy checklist implementation Endoscopy (with lectures by quality officers)

"07:35 huddles" (pre-operative OR briefing following 4 elements) and "surgical time-outs" (pre-operative OR briefing following 9 elements)

Surgical safety checklist

Team briefing structured by a checklist

"Flow checklists" at high-risk points in the patient surgical journey, in addition to the surgical safety checklist

Time-Out Process: (1) team member introductions, (2) safety statement by the time-out leader, (3) addition of two supplemental items to the institutional checklist, and (4) preincision Surgical Care Improvement Project measures
Transitional care unit in

long-term care facility

Operating room

Surgery

Obstetric theatre

Paediatric hospital

Operating room

General surgery room
Neurosurgery in operating

Outcome(s)

GRADE

communication on error, hospital

management promoting safety

Improvement in teamwork and safety climate

Improvement in verification of the patient's identity, awareness of the patient's medical history, medication and allergies, knowledge of the names and roles among the team members, discussion about possible critical events, recording postoperative instructions, communication between team members

Improvement in co-worker and supervisor support, teamwork and communication, job demands and decision authority, characteristics of the unit and intent to leave/transfer unit

Improvement in teamwork, time efficiency, higher confidence levels and more comprehensive operating room setup

Improvement in the Safety Attitude Scores

Improvement in interprofessional communication, familiarity with team members, and checklist compliance

Improvement in team work and communication, patient perception of team communication and teamwork. No significant improvement in team perception

Especially for the nursing personnel, C change the notion of individual advocacy to one of teamwork and being proactive about patient safety

Improvement in communication between the surgeon and the anaesthesiologist. Safety-related issues were better covered. No improvement in awareness. Improvement in unplanned admission rates and number of wound complications

Improvement in number of communication failures and proactive and collaborative team communication

Ambulatory surgery centre Improvement in the perception of patient safety

Improvement in the perception of patient safety, team spirit, voice safety concerns. Does not necessarily reinforce teamwork.

\section{C}

B

C

D

C

C

C

D

C 
Table 1 Summary of results (Continued)

\begin{tabular}{lll}
\hline Authors (year) & Intervention & Setting \\
\hline Merrell et al. 2018 [233] & $\begin{array}{l}\text { Emergency manual consisting of a } \\
\text { set of crisis checklists or cognitive } \\
\text { aids }\end{array}$ & Operating room \\
Mohammed et al. 2013 [234] & Obstetric safe surgery checklist & $\begin{array}{l}\text { Anaesthetists and } \\
\text { obstetricians }\end{array}$ \\
Molina et al. 2016 [235] & Surgical safety checklists & Operating room \\
Nadler et al. 2011 [253] & $\begin{array}{l}\text { Debriefings using video recordings } \\
\text { Pre-operative checklist during time- }\end{array}$ & $\begin{array}{l}\text { Neonatal resuscitation } \\
\text { Out }\end{array}$ \\
Nilsson et al. 2010 [236] & $\begin{array}{l}\text { Operating room } \\
\text { checklist }\end{array}$ & $\begin{array}{l}\text { Operating room at } \\
\text { paediatric hospital }\end{array}$
\end{tabular}

Nundy et al. 2008 [254]

Paige et al. 2009 [255]

Pannick et al. 2017 [256]

Papaconstantinou et al. 2013 [238]

Papaspyros et al. 2010 [257]

Sewell et al. 2011 [239]

Skåre et al. 2018 [258]
Pre-operative briefings using a standardized format (with training session)

Pre-operative briefing protocol

Prospective clinical team surveillance (PCTS): structured daily interdisciplinary briefings to capture staff concerns, with organizational facilitation and feedback

Surgical safety checklist

Surgery

Pre-operative briefing with checklist Cardiac operating room and debriefing

Educational programme focused on Orthopaedic surgery using the surgical safety checklist

Operating room

Operating room

Medical ward

.

(1)


Table 1 Summary of results (Continued)

\begin{tabular}{|c|c|c|c|c|}
\hline Authors (year) & Intervention & Setting & Outcome(s) & GRADE \\
\hline Takala et al. 2011 [240] & Surgical safety checklist & Operating room & $\begin{array}{l}\text { Improvement in confirming patient's } \\
\text { identity, knowledge of names and } \\
\text { roles among team members, } \\
\text { discussing critical events, and fewer } \\
\text { communication failures }\end{array}$ & A \\
\hline Tscholl et al. 2015 [241] & $\begin{array}{l}\text { Anaesthesia pre-induction checklist, } \\
\text { in addition to the surgical safety } \\
\text { checklist }\end{array}$ & Anaesthesiology & $\begin{array}{l}\text { Improvement in information } \\
\text { exchange, knowledge of critical } \\
\text { information, perception of safety in } \\
\text { anaesthesia teams, perceived } \\
\text { teamwork }\end{array}$ & A \\
\hline Urbach et al. 2014 [242] & Surgical safety checklist & Operating room & $\begin{array}{l}\text { Implementation is not associated } \\
\text { with significant reductions in } \\
\text { operative mortality or complications }\end{array}$ & B \\
\hline Wagner et al. 2014 [260] & $\begin{array}{l}\text { Mental health huddles (similar to } \\
\text { safety briefings) to support staff in } \\
\text { discussing and managing client } \\
\text { responsive behaviours }\end{array}$ & Long-term care & $\begin{array}{l}\text { improvement in staff collaboration, } \\
\text { teamwork, support, and } \\
\text { communication }\end{array}$ & D \\
\hline Weiss et al. 2017 [261] & $\begin{array}{l}\text { After events reviews (AER): } \\
\text { assertiveness-specific AER (ASAER) } \\
\text { versus teamwork-generic AER } \\
\text { (TGAER) }\end{array}$ & Healthcare teams & $\begin{array}{l}\text { Improvement in nurses speaking up } \\
\text { following the ASAER in comparison } \\
\text { to TGAER and higher levels of } \\
\text { hierarchy-attenuating beliefs } \\
\text { following the ASAER in comparison } \\
\text { to TGAER }\end{array}$ & C \\
\hline White et al. 2017 [243] & $\begin{array}{l}\text { Four-day pilot course for } \\
\text { implementation of surgical safety } \\
\text { checklist }\end{array}$ & $\begin{array}{l}\text { Hospital (low-income } \\
\text { setting) }\end{array}$ & $\begin{array}{l}\text { Improvement in learning, behaviour } \\
\text { and organizational change (not } \\
\text { hierarchical culture) }\end{array}$ & D \\
\hline Whyte et al. 2009 [262] & $\begin{array}{l}\text { Structured pre-operative team } \\
\text { briefings (using a checklist) }\end{array}$ & Pre-operative teams & $\begin{array}{l}\text { Five types of negative events: the } \\
\text { briefings could mask knowledge } \\
\text { gaps, disrupt positive } \\
\text { communication, reinforce } \\
\text { professional divisions, create tension, } \\
\text { and perpetuate a problematic } \\
\text { culture }\end{array}$ & D \\
\hline Zausig et al. 2009 [263] & $\begin{array}{l}\text { Two different training groups: one } \\
\text { included extensive debriefing of NTS } \\
\text { (resource management, planning, } \\
\text { leadership and communication) and } \\
\text { medical management and the other } \\
\text { included a simpler debriefing that } \\
\text { focused solely on medical } \\
\text { management }\end{array}$ & Anaesthesiology & $\begin{array}{l}\text { Improvement in non-technical skills; } \\
\text { no differences between the groups }\end{array}$ & $D$ \\
\hline
\end{tabular}

Tools: Structuring teamwork: Rounds

Genet et al. 2014 [264]

Henkin et al. 2016 [265]

Li et al. 2018 [266]

O'Leary et al. 2010 [267]

O'Leary et al. 2011 [268]
Respiratory therapist (RT)-led interdisciplinary rounds using a scripted tool (with education session)

Bedside rounding: inclusion of nurses in morning rounds with the medicine teams at the patients' bedside, using a checklist

Interprofessional Teamwork Innovation Model (ITIM): structured daily rounds

Structured Interdisciplinary Rounds combined a structured format for communication and a forum for regular interdisciplinary meetings

Structured Interdisciplinary Rounds:
Neonatal ICU

Improvement in communication, teamwork, and timeliness of completing respiratory orders

General medicine inpatient Improvement in the perceptions of teaching unit

nurse-physician teamwork

Academic medical centre

Improvement in communication among team members and overall time savings. Reduction in 30-day same-hospital readmissions, no impact on 30-day same-hospital ED visits or costs

Tertiary care teaching hospital

Improvement in teamwork climate in intervention group (compared to control group)

General medical unit in 
Table 1 Summary of results (Continued)

\begin{tabular}{ll}
\hline Authors (year) & Intervention \\
\hline & combined a structured format for \\
& communication with a forum for \\
& regular interdisciplinary meetings \\
O'Leary et al. 2015 [269] & $\begin{array}{l}\text { Structured Interdisciplinary Rounds } \\
\text { and prepared nurse-physician co- } \\
\text { leadership }\end{array}$ \\
Young et al. 2017 [270] & Multidisciplinary Bedside Rounding \\
& Initiative, which included creating \\
& nursing availability, streamlining \\
& provider communication, and \\
performance monitoring and \\
feedback
\end{tabular}

\begin{tabular}{lll} 
Setting & Outcome(s) & GRADE \\
\hline hospital & $\begin{array}{l}\text { communication and collaboration } \\
\text { with hospitalists, teamwork and } \\
\text { safety climate }\end{array}$ \\
General medical units & $\begin{array}{l}\text { Improvement in teamwork but no } \\
\text { reduction in Adverse Events }\end{array}$ \\
Hospital & Improvement in teamwork climate, D \\
& $\begin{array}{l}\text { nurse job satisfaction, and early } \\
\text { discharges }\end{array}$
\end{tabular}

Tools: Facilitating teamwork

Butler et al. 2018 [271]

Telemedicine technology in care delivery

Chu-Weininger et al. 2010 [272]

Doyle et al. 2016 [273]

Foo et al. 2015 [274]

Letchworth et al. 2017 [275]

O'Connor et al. 2009 [276]

Yeh et al. 2016 [277]

Tools: Triggering teamwork
Remote monitoring by intensivists using telemedicine technology (tele$\mathrm{ICU})$

Remote information technology (education session, teleconferences, web-based team case presentations)

Mobile task management tool (digitize patient flow and provide real-time visibility over clinical decision making and task performance)

MedNav; a decision support tool on a tablet or mobile phone with integrated vocal prompts and visual cues

Using wireless e-mail in order to send information-rich, specific, legible, and time-stamped messages

Ping-pong-type multidisciplinary reflective e-communication (within web-based integrated information platform)
Intensive care

Mental health services for older people

Acute general surgical service

Maternity teams

Intensive care

Radiation oncology
Aberdeen and Byrne 2018 [278]

Concept mapping visually representing a patient's situation

Ainsworth et al. 2013 [279]

Bennett et al. 2015 [280]

Door Communication Card (DCC) to improve goal alignment

Sharing clinical cases and stories about patients (during workshops)

Residential aged care facilities

Surgical ICU academic military medical

Primary care clinical setting Helped in bonding around their care, build supportive relationships,

Daley et al. 2012 [281]
Clinical dashboard system shared mission of patient-centred enhance compassion for patients, communicate and resolve conflict, better understand workflows and job roles, develop trust, and increase morale

No differences in teamwork experiment group and safety climate

Improvement in professional development, perceived peer and reduce travel time

Improvement in working efficiency of junior clinical staff

Improvement in teamwork based on B all domains of Clinical Teamwork Scale and Global Assessment of Obstetric Team Performance

Improvement in communication, team relationships, staff satisfaction, and patient care

Higher Timeliness, Notating convenience, Information completeness, Feedback convenience, Communication confidence, Communication effectiveness, Review convenience and overall satisfaction

Improvement in effectiveness of care planning and knowledge increase of dementia care

No improvement in goal alignment

Improvement in access to information, communication and information sharing, staff awareness, and data quality groups. Higher workload in

Improvement in teamwork climate

B 
Table 1 Summary of results (Continued)

\begin{tabular}{|c|c|c|c|c|}
\hline Authors (year) & Intervention & Setting & Outcome(s) & GRADE \\
\hline O'Neil et al. 2017 [282] & $\begin{array}{l}\text { Thought for the Day (TOD) } \\
\text { intervention; a short reflection on a } \\
\text { piece of poetry, music, or religious } \\
\text { writing }\end{array}$ & Inpatient palliative care & $\begin{array}{l}\text { Improvement in perception of } \\
\text { teamwork. Coming together as an } \\
\text { interdisciplinary team for a time to } \\
\text { reflect is valued }\end{array}$ & $\mathrm{D}$ \\
\hline Siegele 2009 [283] & $\begin{array}{l}\text { The Daily Goals Tool (DGT) and Daily } \\
\text { Goals Tool Reference (DGTR) }\end{array}$ & Surgical intensive care & $\begin{array}{l}\text { Helps in simplifying complex tasks, } \\
\text { improving teamwork, promoting } \\
\text { effective communication and shared } \\
\text { decision making, and enhancing } \\
\text { patient safety }\end{array}$ & D \\
\hline Stoller et al. 2010 [284] & $\begin{array}{l}\text { Respiratory therapy }(\mathrm{RT}) \text { business } \\
\text { scorecard that compared target }\end{array}$ & $\begin{array}{l}\text { Respiratory therapy } \\
\text { departments }\end{array}$ & $\begin{array}{l}\text { Improvement in teamwork among } \\
\text { RT departments and outcomes }\end{array}$ & $\mathrm{D}$ \\
\hline
\end{tabular}

Organizational (re)design

Barry et al. 2016 [285]

de Beijer et al. 2016 [286]

Clements et al. 2015 [287]

Deneckere et al. 2013 [288]

Fernandez et al. 2010 [289]

Fogel et al. 2016 [290]

Frykman et al. 2014 [291]

Greene et al. 2015 [292] scorecard that compared target goals with actual monthly performance

Behavioural Health Interdisciplinary Program (BHIP) team model as an innovative approach to transform VHA general outpatient mental health delivery, include holding daily huddles and longer weekly interdisciplinary team meetings

Clinical pathways: standardizing treatment and communication methods, delegating tasks from medical specialists to nurses, and providing nurses with their own consultation room

Allocating the most senior nurse as team leader of trauma patient assessment and resuscitation

Care pathways: (1) Formative evaluation of the teams' performance before implementation (2) Evidence-based Kl, and (3) Training in pathway development

Two models: The multifaceted Shared Care in Nursing (SCN) model of nursing careinvolved team work, leadership and professional development. In the Patient Allocation (PA) model one nurse was responsible for the care of a discrete group of patients

Patient-focused primary care redesign

Multiprofessional teamwork involving changes in work processes, with task-generated feedback, managerial feedback, aimed at increasing interprofessional collaboration

Innovative compensation model: replaced fee-for-service payment with a largely team based, qualityfocused payment, $40 \%$ of compensation was based upon the clinic-
Veterans Health Administration mental health care outpatient clinic

Emergency department

Acute hospital

General medical and surgical wards in tertiary teaching hospital

Continuity clinic settings mprovement in teamwork training, teamwork among residents, perception of overall quality of care in clinic, and that physicians, nurses, and administrative staff worked together to optimize patient flow

Emergency department

Enabled teamwork
Mixed results: quality improvement for the team and less patient "dumping," or shifting patients with poor outcomes to other clinicians, but also lack of control and 
Table 1 Summary of results (Continued)

\begin{tabular}{ll}
\hline Authors (year) & Intervention \\
\hline Hern et al. 2009 [293] & $\begin{array}{l}\text { level quality performance, and an } \\
\text { additional } 10 \% \text { was based upon the } \\
\text { clinic-level patient's experience }\end{array}$ \\
& $\begin{array}{l}\text { Quality improvement intervention: } \\
\text { creation of team structures linking } \\
\text { faculty advisors and residents with } \\
\text { patients, intra-team management of } \\
\text { office tasks, and the implementation } \\
\text { of multidisciplinary team meetings }\end{array}$
\end{tabular}

Hung et al. 2018 [294]

O'Leary et al. 2009 [295]

Pan et al. 2017 [296]

Parush et al. 2017 [297]

Pati et al. 2015 [298]

Stavroulis et al. 2013 [299]

Stepaniak et al. 2012 [300]

Programme

Basson et al. 2018 [301]

Bunnell et al. 2013 [302]
Redesign consisting of multiple workflow changes: (1) "5S" standardization of medical equipment, supplies and education materials in patient exam rooms, (2) redesign of call centre functions, (3) co-location of existing care teams and (4) redesign of care team roles and workflows

Localizing physicians to specific patient care units

An operating room (OR) assistant using an instructional supervision programme

Employ technological cognitive aids at ED

Decentralized unit operations and the corresponding physical design

Integrated theatre environment: a superior operating environment in which the laparoscopic equipment and multiple flat-screen monitors are permanently installed to be operational on demand inside the theatre

Fixed operating room (OR) teams for Operating room (bariatric a day instead of OR teams that vary surgery) during the day

Multifaceted intervention consisting of monthly walking rounds by the director and an interactive learning session focused of feedback of culture data, educational training programme, and unit-based programme for safety

For each identified risk area, agreements about roles, responsibilities and behaviours of each team member were made. Tools were developed and systems modified to enhance situational awareness and a shared mental model among team members, and to support implementation of the agreements

\section{Setting}

Family medicine

Ambulatory care primary care departments

Hospital

Operating room

Emergency Department

Inpatient units

Operating room

Veterans administration hospital leaders

Ambulatory clinical oncology practice
Outcome(s)

GRADE

colleagues riding the coattails of

higher performers. mixed results:

greater interaction with colleagues,

but also an increase in tension

Improvement in perceptions of continuity of patient care, office efficiency, and team communication

C

Improvement in teamwork, participation in decisions to improve care by physicians, engagement among physicians and motivation among Non-physicians staff

Nurses and physicians wereable to B identify one another and communicated more frequently

Improvement in first cases that started on time, percentage of teamwork score and patient satisfaction

Improvement in teamwork; overall communication, situational awareness (as measured by CTS and not SAGAT), and decision making

Potentially improvement in quality of work

Improvement in perceived efficiency, teamwork and stress levels

Reduced procedure durations and improved teamwork and safety climate, without adverse effects on patient outcomes

No improvement on most items of the SAQ and AHRQ Hospital Safety Survey. Improvement in responding to errors and expressing disagreement with physicians.

Decrease of perception of leadership's safety efforts and levels of staffing

Improvement in patient satisfaction scores regarding coordination of care, efficiency safety of care, more respectful behaviour, relationships among team members. No significant improvement in noncommunication 
Table 1 Summary of results (Continued)

\begin{tabular}{|c|c|c|c|c|}
\hline Authors (year) & Intervention & Setting & Outcome(s) & GRADE \\
\hline Braithwaite et al. 2012 [303] & $\begin{array}{l}\text { System-wide intervention promoting } \\
\text { interprofessional collaboration; } \\
\text { implementing educational } \\
\text { workshops and seminars, feedback } \\
\text { sessions, project, and other } \\
\text { initiatives }\end{array}$ & $\begin{array}{l}\text { Health professionals across } \\
\text { entire health system }\end{array}$ & $\begin{array}{l}\text { Most agreement on improvement in } \\
\text { sharing of knowledge between } \\
\text { professions and improved quality of } \\
\text { patient care, and least agreement } \\
\text { that between-professional rivalries } \\
\text { had lessened and communication } \\
\text { and trust between professions } \\
\text { improved }\end{array}$ & B \\
\hline Carney et al. 2011 [304] & $\begin{array}{l}\text { Medical team training programme: } \\
\text { preparations, learning sessions, } \\
\text { implementing projects including } \\
\text { briefing and debriefing, coaching }\end{array}$ & $\begin{array}{l}\text { Operating room in } \\
\text { Veterans Health } \\
\text { Administration }\end{array}$ & $\begin{array}{l}\text { Improved perceptions of safety } \\
\text { climate }\end{array}$ & B \\
\hline Carney et al. 2011 [305] & $\begin{array}{l}\text { Medical team training programme: } \\
\text { preparations, learning sessions, } \\
\text { implementing projects including } \\
\text { briefing and debriefing, coaching }\end{array}$ & $\begin{array}{l}\text { Veterans Health } \\
\text { Administration }\end{array}$ & Improvement in teamwork climate & B \\
\hline Costello et al. 2011 [306] & $\begin{array}{l}\text { OR Transformation Project: OR day } \\
\text { redesign, workflow, human } \\
\text { resources analysis, supply and } \\
\text { technology, and quality of work life }\end{array}$ & Operating room & $\begin{array}{l}\text { Improvement in work practices, } \\
\text { recognition/ compensation, } \\
\text { communication, commitment, } \\
\text { physical/environmental safety, } \\
\text { teamwork, and respect }\end{array}$ & C \\
\hline Ginsburg and Bain 2017 [307] & $\begin{array}{l}\text { Multifaceted intervention } \\
\text { programme to promote speaking }\end{array}$ & $\begin{array}{l}\text { Emergency department } \\
\text { and intensive care }\end{array}$ & $\begin{array}{l}\text { Improvement in team climate score } \\
\text { at follow-up }\end{array}$ & B \\
\hline
\end{tabular}
up and teamwork consisting a roleplaying simulation workshop, discussion briefings and other department-led initiatives such as 10-min staff huddles

Hilts et al. 2013 [308]

The Quality in Family Practice (QIFP) programme encompasses clinical and practice management using a comprehensive tool of family practice indicators

Hsu et al. 2015 [309]

Multifaceted intervention included Comprehensive Unit-based Safety Program (CUSP), the daily goals communication tool, and 5 evidence-based practices (i.e. hand washing, using full-barrier precautions during the insertion of central venous catheters, cleaning the skin with chlorhexidine, avoiding the femoral site, and removing unnecessary catheters)

Hsu et al. 2014 [310]

Team Resource Management (TRM) programme: simulative learning workshop (e.g. lectures, videos, casebased interactive discussions), focus group interviews, develop TRMbased checklists, working sheets, and re-designed organ procurement and transplantation processes, video skill demonstration and training, case reviews and feedback activities

Hospital-wide quality improvement programme: forming committee to review the system, implemented a dedicated communication system, standardizationon of role, training, implementing a standard reporting system

Academic primary care Improvement in understanding of team roles and relationships, teamwork, flattening of hierarchy through empowerment

Adult intensive care

Improvement in safety climate, job satisfaction, and working conditions teamwork (i.e. teamwork framework, leadership, situational awareness, communication, mutual support); no error in communication or patient identification was noted

\section{Hospital}

Improvement in safety attitude (i.e. sharing information, training, medical error reporting, safety climate, job satisfaction, communication, hospital management quality) 
Table 1 Summary of results (Continued)

\begin{tabular}{ll}
\hline Authors (year) & Intervention \\
\hline & sessions, action periods to develop \\
& improvement plans, and summative \\
& congresses supported by QI \\
& coaches, teleconferences, and a \\
& web-based virtual office \\
& Safety Program for Surgery: \\
& Comprehensive Unit-based Safety \\
& Program (CUSP) and individualized \\
Lin et al. 2018 [313] &
\end{tabular}

McArdle et al. 2018 [314]

McCulloch et al. 2017 [315]

Neily et al. 2010 [316]

Neily et al. 2010 [5]

Pettker et al. 2011 [317]

Pitts et al. 2017 [318]

Pronovost et al. 2008 [319]
Safety Program for Perinatal Care (SPPC, adapted CUSP): TeamSTEPPS teamwork and communication framework and tools, applying safety science principles (standardization, independent checks, and learn from defects), and establishing an in situ simulation programme

Four-month safety improvement interventions, using teamwork training (TT), systems redesign and standardization (SOP), Lean qualityimprovement, $\mathrm{SOP}+\pi$ combination, or Lean+TT combination

Medical team training programme: preparation, learning session, implementing briefings, debriefings and other projects (i.e. SBAR, Interdisciplinary rounds, Fatigue management), follow-up coaching

Medical team training programme: preparation, learning session, implementing projects, follow-up coaching

Comprehensive Obstetrics Patient Safety Program: (1) obstetrics patient safety nurse, (2) protocol-based standardization of practice, (3) CRM training, (4) oversight by a patient safety committee, (5) 24-h obstetrics hospitalist, and (6) anonymous event reporting system

Comprehensive Unit-based Safety Program (CUSP): training, safety assessment, select safety priorities

Comprehensive Unit-based Safety Program including implementing CUSP (i.e. 6-step iterative process), daily goals communication strategy, and toolkit included materials for staff education, redesign of work

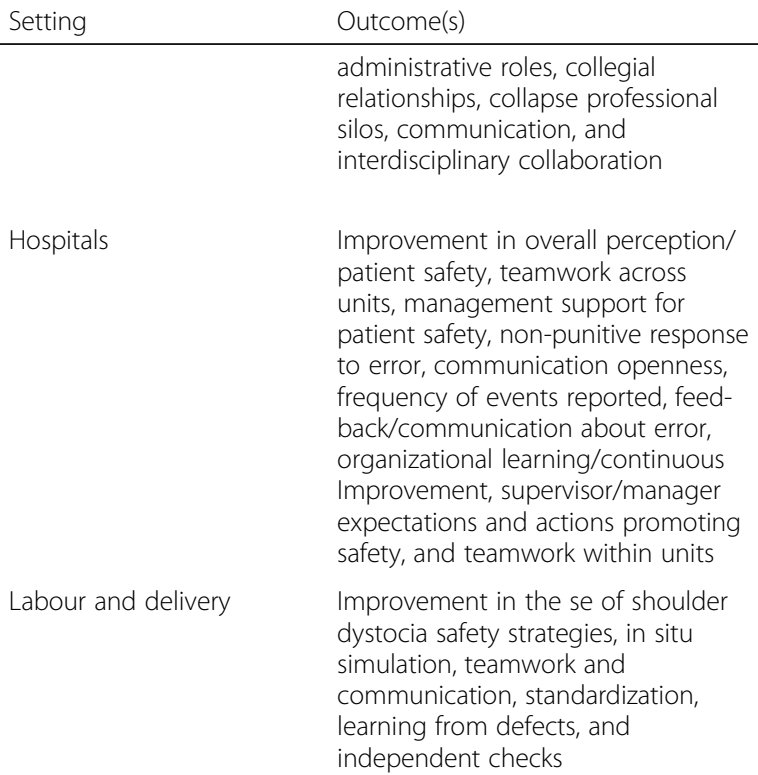

administrative roles, collegial

relationships, collapse professional

silos, communication, and

interdisciplinary collaboration

Hospitals

mprovement in overall perception/ patient safety, teamwork across units, management support for patient safety, non-punitive response to error, communication openness, frequency of events reported, feedback/communication about error, organizational learning/continuous Improvement, supervisor/manager expectations and actions promoting safety, and teamwork within units

Labour and delivery

Improvement in the se of shoulder dystocia safety strategies, in situ simulation, teamwork and communication, standardization, learning from defects, and independent checks

Operating room

$\Pi$ : improvement in non-technical skills and WHO compliance, but not technical performance. Systems interventions (Lean and SOP): improvement in non-technical skills and technical performance, $\mathrm{WHO}$ compliance. Combined interventions: improvement in all performance measures except WHO timeout attempts, whereas single approaches improved WHO compliance less and failed to improve technical performance

Surgical care in Veterans Health Administration

Improvement in teamwork, efficiency, avoiding an undesirable event

Lower surgical mortality and improvement in open communication and staff awareness Veterans Health Administration

Hospital

Improvement in proportion of staff members with favourable perceptions of teamwork culture, safety culture, job satisfaction, and management. No significant improvement in stress recognition

Primary care

No significant improvement in safety climate and teamwork

Intensive care 
Table 1 Summary of results (Continued)

\begin{tabular}{|c|c|c|c|c|}
\hline Authors (year) & Intervention & Setting & Outcome(s) & GRADE \\
\hline & $\begin{array}{l}\text { processes, support of local opinion } \\
\text { leaders, and evaluation of } \\
\text { performance }\end{array}$ & & & \\
\hline Sexton et al. 2011 [320] & $\begin{array}{l}\text { Comprehensive Unit-based Safety } \\
\text { Program (CUSP): educate teams, } \\
\text { identify, prioritize, and eliminate pa- } \\
\text { tient safety hazards, senior leader's } \\
\text { role, tools for learning and improv- } \\
\text { ing communication }\end{array}$ & Intensive care & Improvement in safety climate & B \\
\hline Stapley et al. 2017 [321] & $\begin{array}{l}\text { The Situation Awareness For } \\
\text { Everyone (SAFE) programme: } \\
\text { huddle, SBAR, and paediatric early } \\
\text { warning systems (PEWS) }\end{array}$ & Clinical wards & $\begin{array}{l}\text { Improvement in awareness of } \\
\text { important issues, communication, } \\
\text { teamwork, and a culture of } \\
\text { increased efficiency, anticipation and } \\
\text { planning on the ward. But added } \\
\text { pressure on staff time and workload, } \\
\text { and the potential for junior nurses } \\
\text { to be excluded from involvement }\end{array}$ & D \\
\hline Timmel et al. 2010 [322] & $\begin{array}{l}\text { Comprehensive Unit-Based Safety } \\
\text { Program (CUSP) including } 6 \text { steps: } \\
\text { Science of safety training educa- } \\
\text { tional curriculum, Identify safety haz- } \\
\text { ards, Senior executive partnership, } \\
\text { Learn from defects, Implement im- } \\
\text { provement tools, such as team- } \\
\text { based goals sheet, including nurses } \\
\text { on rounds to form an interdisciplin- } \\
\text { ary team }\end{array}$ & Surgical inpatient units & $\begin{array}{l}\text { Improvement in safety climate, } \\
\text { teamwork climate, and nurse } \\
\text { turnover rates }\end{array}$ & B \\
\hline Wolf et al. 2010 [323] & $\begin{array}{l}\text { Medical team training programme: } \\
\text { preparation, classroom learning } \\
\text { session, checklist-guided briefings } \\
\text { and debriefings, formation of a } \\
\text { problem-solving Executive Commit- } \\
\text { tee, follow-up and feedback }\end{array}$ & $\begin{array}{l}\text { Operating room in } \\
\text { Veterans Health } \\
\text { Administration }\end{array}$ & $\begin{array}{l}\text { Improvement in case delays, mean } \\
\text { case score, frequency of pre- } \\
\text { operative delays, handoff issues, } \\
\text { equipment issues/delays, perceived } \\
\text { management and working condi- } \\
\text { tions. No significant improvement in } \\
\text { teamwork climate, safety climate, } \\
\text { job satisfaction, stress recognition }\end{array}$ & B \\
\hline
\end{tabular}

previous types of interventions (i.e. training, tools, and/ or redesign). Table 2 presents the (sub)categorization, number of studies, and a short description of each (sub)category.

\section{Overall findings Type of intervention}

The majority of studies evaluated a training. Simulationbased training is the most frequently researched type of team training.

\section{Setting}

Most of the articles researched an acute hospital setting. Examples of acute hospital settings are the emergency department, operating theatre, intensive care, acute elderly care, and surgical unit. Less attention was paid to primary care settings, nursing homes, elderly care, or long-term care in general.

\section{Outcome}

Interventions focused especially on improving nontechnical skills, which refer to cognitive and social skills such as team working, communication, situational awareness, leadership, decision making, and task management [21]. Most studies relied on subjective measures to indicate an improvement in team functioning, with only a few studies (also) using objective measures. The Safety Attitude Questionnaire (SAQ) and the NonTechnical Skills (NOTECHS) tool are frequently used instruments to measure perceived team functioning.

\section{Quality of evidence}

A bulk of the studies had a low level of evidence. A preand post-study is a frequently used design. In recent years, an increasing number of studies have used an action research approach, which often creates more insight into the processes of implementing and tailoring an intervention than the more frequently used designs (e.g. Random Control Trial and pre-post surveys). However, these valuable insights are not fully appreciated within the GRADE scale.

The findings per category will be discussed in greater detail in the following paragraphs. 
Table 2 Categorization of results

\begin{tabular}{|c|c|c|}
\hline Interventions & $n$ & Description \\
\hline 1. Training & 174 & $\begin{array}{l}\text { "A systematic process through which a team is trained to master and improve different aspects of team } \\
\text { functioning." [8] }\end{array}$ \\
\hline \multicolumn{3}{|l|}{ 1.1 Principle-based training } \\
\hline a. CRM-based training & 40 & $\begin{array}{l}\text { "Training based on a management concept used in the aviation industry to improve teamwork. CRM } \\
\text { encompasses a wide range of knowledge, skills, and attitudes including communication, situational } \\
\text { awareness, problem solving, decision making, and teamwork." [8] }\end{array}$ \\
\hline b. TeamSTEPPS & 28 & $\begin{array}{l}\text { A specific set of strategies and techniques, aimed at optimizing patient outcomes by improving } \\
\text { communication and teamwork skills among healthcare professionals. (https://www.ahrq.gov/ } \\
\text { teamstepps/index.html) }\end{array}$ \\
\hline $\begin{array}{l}\text { 1.2 Method-based training: } \\
\text { Simulation-based training }\end{array}$ & 69 & "Training that recreates characteristics of the real world." [8] \\
\hline 1.3 General team training & 37 & $\begin{array}{l}\text { General team training includes studies that each has a unique combination of principles and learning } \\
\text { methods. }\end{array}$ \\
\hline 2. Tools & 83 & Specific instruments that teams can use to improve teamwork [8] \\
\hline 2.1 Structuring tools & & Tools that are used to partly standardize the process of team interaction. \\
\hline a. SBAR & 11 & $\begin{array}{l}\text { The SBAR (Situation, Background, Assessment, Recommendation) is a framework for communication } \\
\text { between team members about a patient's condition. (www.ihi.org) }\end{array}$ \\
\hline b. (De)briefing checklist & 51 & $\begin{array}{l}\text { A tool that creates an opportunity for professionals to systematically communicate and discuss } \\
\text { (potential) issues before or after delivering care to a patient, based on a structured format of elements/ } \\
\text { topics; checklist. }\end{array}$ \\
\hline c. Rounds & 7 & A structured interdisciplinary meeting around a patient. \\
\hline 2.2 Facilitating tools & 7 & Tools (often technology) that facilitate communication between team members. \\
\hline 2.3 Triggering tools & 7 & Tools that help provide information (e.g. dashboards) to incentivize team interaction. \\
\hline 3. Organizational (re)design & 16 & $\begin{array}{l}\text { Design or redesign of organizational structures with the aim of improving team processes and team } \\
\text { functioning. }\end{array}$ \\
\hline 4. Programme & 24 & $\begin{array}{l}\text { A combination of interventions (training, tools, and/or organizational (re)design) bundled in a program } \\
\text { that aims to improve team functioning. }\end{array}$ \\
\hline Total & 297 & \\
\hline
\end{tabular}

\section{Training}

CRM and TeamSTEPPS are well-known principle-based trainings that aim to improve teamwork and patient safety in a hospital setting. Both types of training are based on similar principles. CRM is often referred to as a training intervention that mainly covers non-technical skills such as situational awareness, decision making, teamwork, leadership, coping with stress, and managing fatigue. A typical CRM training consists of a combination of information-based methods (e.g. lectures), demonstration-based methods (e.g. videos), and practice-based methods (e.g. simulation, role playing) [9]. However, CRM has a management concept at its core that aims to maximize the use of all available resources (i.e. equipment, time, procedures, and people) [324]. CRM aims to prevent and manage errors through avoiding errors, trapping errors before they are committed, and mitigating the consequences of errors that are not trapped [325]. Approximately a third of CRM-based trainings include the development, redesign or implementation of learned CRM techniques/tools (e.g. briefing, debriefing, checklists) and could therefore also be categorized in this review under programme [39, 40, 42, $51,56,58,59,61,62]$.

The studies show a high variety in the content of CRM training and in the results measured. The majority of the studies claim an improvement in a number of non-technical skills that were measured, but some also show that not all non-technical skills measured were improved [43, 47, 66]. Moreover, the skills that did or did not improve differed between the studies. A few studies also looked at outcome measures (e.g. clinical outcomes, error rates) and showed mixed results [49, 52, 53]. Notable is the increasing attention toward nursing CRM, which is an adaptation of CRM to nursing units [66, 67]. Most studies delivered a low to moderate quality level of evidence. Although most studies measured the effect of CRM over a longer period of time, most time periods were limited to one or two evaluations within a year. Savage et al. [58] and Ricci et al. [56] note the importance of using a longer time period.

As a result of experienced shortcomings of CRM, Team Strategies and Tools to Enhance Performance and Patient Safety (TeamSTEPPS) has evolved (since 2006). 
TeamSTEPPS is a systematic approach designed by the Agency for Healthcare Research and Quality (AHRQ) and the Department of Defense (DoD) to enhance teamwork skills that are essential to the delivery of quality and safe care. Some refer to TeamSTEPPS as "CRM and more". TeamSTEPPS provides an approach on preparing, implementing, and sustaining team training. It is provided as a flexible training kit and facilitates in developing a tailored plan. It promotes competencies, strategies, and the use of standardized tools on five domains of teamwork: team structure, leadership, communication, situational monitoring, and mutual support. In addition, TeamSTEPPS focuses on change management, coaching, measurement, and implementation. Notable is that even though the TeamSTEPSS training is most likely to differ across settings as it needs to be tailored to the situational context, articles provide limited information on the training content. All studies report improvements in some nontechnical skills (e.g. teamwork, communication, safety culture). Combining non-technical skills with outcome measures (e.g. errors, throughput time) seemed more common in this category. Half of the studies delivered a moderate to high quality of evidence.

Simulation-based training uses a specific method as its core, namely, simulation, which refers to "a technique to replace or amplify real-patient experiences with guided experiences, artificially contrived, that evokes or replicates substantial aspects of the real world in a fully interactive manner" [326]. The simulated scenarios that are used can have different forms (e.g. in situ simulation, in centre simulation, human actors, mannequin patients) and are built around a clinical scenario (e.g. resuscitation, bypass, trauma patients) aiming to improve technical and/or nontechnical skills (e.g. interprofessional collaboration, communication). We only identified studies in a hospital setting, which were mostly focussed on an emergency setting. All studies reported improvements in some non-technical skills (e.g. teamwork behaviour, communication, shared mental model, clarity in roles and responsibilities). In addition, some studies report non-significant changes in non-technical skills [98, 137, 140, 155]. Some studies also looked at technical skills (e.g. time spend) and presented mixed results $[63,112,152,159]$. Sixty-nine studies focused on simulation-based training, of which 16 studies delivered a moderate to high quality of evidence.

General team training does not focus on one specific training principle or method. It often contains multiple educational forms such as didactic lectures, interactive sessions, and online modules. General team training focuses on a broad target group and entails for example team building training, coaching training, and communication skills training. Due to the broad scope of this category, high variation in outcomes is noted, although many positive outcomes were found. Most studies have a low to very low level of evidence.

\section{Tools}

Tools are instruments that could be implemented relatively independently in order to structure, facilitate or trigger teamwork.

\section{Structuring tools}

Teamwork can be structured by using the structured communication technique SBAR (Situation, Background, Assessment, and Recommendation), (de)briefing checklists, and rounds.

$S B A R$ is often studied in combination with strategies to facilitate implementation, such as didactic sessions, training, information material, and modifying SBAR material (e.g. cards) [202, 204, 206-208, 211]. In addition, this subcategory entails communication techniques similar or based on SBAR [203, 205, 209, 210, 212]. One study focused on nursing homes, while the remaining studies were performed in a hospital setting. Most studies found improvements in communication; however, a few found mixed results [208, 209]. Only (very) low-level evidence studies were identified.

Briefings and debriefings create an opportunity for professionals to systematically communicate and discuss (potential) issues before or after delivering care to a patient, based on a structured format of elements/topics or a checklist with open and/or closed-end questions. Studies on (de)briefing checklists often evaluate the implementation of the World Health Organization surgical safety checklist (SSC), a modified SSC, SSC-based checklist, or a safety checklist in addition to the SSC. The SSC consists of a set of questions with structured answers that should be asked and answered before induction of anaesthesia, before skin incision, and before the patient leaves the operating theatre. In addition, several studies presented checklists aiming to better manage critical events [221, 223, 233]. Only one study on SSC was conducted outside the surgery department/operating theatre (i.e. cardiac catheterization laboratory [222]). However, similar tools can also be effective in settings outside the hospital, as shown by two studies that focused on the long-term care setting $[249,260]$. Overall, included studies show that (de)briefing checklists help improve a variety of non-technical skills (e.g. communication, teamwork, safety climate) and objective outcome measures (e.g. reduced complications, errors, unexpected delays, morbidity). At the same time, some studies show mixed results or are more critical of its (sustainable) effect [215, 222, 231, 242]. Whyte et al. [262] pointed 
out the complexity of this intervention by presenting five paradoxical findings: team briefings could mask knowledge gaps, disrupt positive communication, reinforce professional divisions, create tension, and perpetuate a problematic culture. The quality of evidence varied from high to very low (e.g. Whyte et al. [262]), and approximately one third presented a high or moderate quality of evidence. Debriefings can also be used as part of a training, aiming to provide feedback on trained skills. Consequently, some articles focused on the most suitable type of debriefing in a training setting (e.g. video-based, selfled, instructor-led) $[245,246,253,263]$ or debriefing as reflection method to enhance performance $[258,261]$.

Rounds can be described as structured interdisciplinary meetings around a patient. Rounds were solely researched in hospital settings. Five studies found improvements in non-technical skills, one study in technical skills, and one study reported outcomes but found no improvement. Three studies presented a moderate level of evidence, and the others presented a (very) low level.

\section{Facilitating tools}

Teamwork can be facilitated through technology. Technology, such as telecommunication, facilitates teamwork as it creates the opportunity to involve and interact with professionals from a distance [271-273]. Technology also creates opportunities to exchange information through information platforms [276, 277]. Most studies found positive results for teamwork. Studies were performed in a hospital setting and presented a level of evidence varying from moderate to very low.

\section{Triggering tools}

Teamwork could be triggered by tools that monitor and visualize information, such as (score) cards and dashboards [278, 279, 281, 283, 284]. The gathered information does not echo team performance but creates incentives for reflecting on and improving teamwork. Team processes (e.g. trust, reflection) are also triggered by sharing experiences, such as clinical cases and stories, thoughts of the day [280,282]. All seven studies showed improvements in non-technical skills and had a very low level of evidence.

\section{Organizational (re)design}

In contrast with the previous two categories, organizational (re)design is about changing organizational structures. Interventions can be focused on several elements within a healthcare organization, such as the payment system [292] and the physical environment [299], but are most frequently aimed at standardization of processes in pathways [286, 288] and changing roles and responsibilities [287, 289, 298], sometimes by forming dedicated teams or localizing professionals to a certain unit or patient [290, 291, 295, 300]. Most studies found some improvements of non-technical skills; however, a few found mixed results. Only four studies had a moderate level of evidence, and the others had a (very) low level.

\section{Programme}

A programme most frequently consists of a so-called $\mathrm{Hu}$ man Resource Management bundle that combines learning and educational sessions (e.g. simulation training, congress, colloquium), often multiple tools (e.g. rounds, SBAR), and/or structural intervention (e.g. meetings, standardization). Moreover, a programme frequently takes the organizational context into account: developing an improvement plan and making choices tailored to the local situation. A specific example is the "Comprehensive UnitBased Safety Program" (CUSP) that combines training (i.e. science of safety training educational curriculum, identify safety hazards, learn from defects) with the implementation of tools (e.g. team-based goal sheet), and structural intervention (i.e. senior executive partnership, including nurses on rounds, forming an interdisciplinary team) [309, 319, 322]. Another example is the medical team training (MTT) programme that consists of three stages: (1) preparation and follow-up, (2) learning session, (3) implementation and follow-up. MTT combines training, implementation of tools (briefings, debriefing, and other projects), and follow-up coaching [5, 304, 305, 316]. MMT programmes are typically based on CRM principles, but they distinguish themselves from the first category by extending their programme with other types of interventions. Most studies focus on the hospital setting, with the exception of the few studies performed in the primary care, mental health care, and healthcare system. Due to the wide range of programmes, the outcomes were diverse but mostly positive. The quality of evidence varied from high to very low.

\section{Conclusion and discussion}

This systematic literature review shows that studies on improving team functioning in health care focus on four types of interventions: training, tools, organizational (re)design, and programmes. Training is divided into principle-based training (subcategories: CRM-based training and TeamSTEPPS), method-based training (simulation-based training), and general team training. Tools are instruments that could be implemented relatively independently in order to structure (subcategories: SBAR, (de)briefing checklists, and rounds), facilitate (through communication technology), or trigger teamwork (through information provision and monitoring). Organizational (re)design focuses on intervening in structures, which will consequently improve team functioning. Programmes refer to a combination of different types of interventions. 
Training is the most frequently researched intervention and is most likely to be effective. The majority of the studies focused on the (acute) hospital care setting, looking at several interventions (e.g. CRM, TeamSTEPPS, simulation, SBAR, (de)briefing checklist). Longterm care settings received less attention. Most of the evaluated interventions focused on improving nontechnical skills and provided evidence of improvements; objective outcome measures also received attention (e.g. errors, throughput time). Looking at the quantity and quality of evidence, principle-based training (i.e. CRM and TeamSTEPPS), simulation-based training, and (de)briefing checklist seem to provide the biggest chance of reaching the desired improvements in team functioning. In addition, programmes, in which different interventions are combined, show promising results for enhancing team functioning. The category programmes not only exemplify this trend, but are also seen in principle-based training.

Because this review is an update of our review conducted in 2008 (and published in 2010) [8], the question of how the literature evolved in the last decade arises. This current review shows that in the past 10 years significantly more research has focused on team interventions in comparison to the previous period. However, the main focus is on a few specific interventions (i.e. CRM, simulation, (de)briefing checklist). Nevertheless, an increasing number of studies are evaluating programmes in which several types of interventions are combined.

- Training: There has been a sharp increase in research studying team training (from 32 to 173 studies). However, the majority of these studies still look at similar instruments, namely, CRM-based and simulation-based training. TeamSTEPPS is a standardized training that has received considerable attention in the past decade. There is now a relatively strong evidence for the effectiveness of these interventions, but mostly for the (acute) hospital setting.

- Tools: There is also a substantial increase (from 8 to 84 studies) in studies on tools. Again, many of these studies were in the same setting (acute hospital care) and focused on two specific tools, namely, the SBAR and (de)briefing checklist. Although the level of evidence for the whole category tools is ambiguous, there is relatively strong evidence for the effectiveness of the (de)briefing checklist. Studies on tools that facilitate teamwork ascended the past decade. There is limited evidence that suggests these may enhance teamwork. The dominant setting was again hospital care, though triggering tools were also studied in other settings such as acute elderly care and clinical primary care. Moreover, most studies had a (very) low quality of evidence, which is an improvement compared to the previous review that solely presented (very) low level of evidence.

- Organizational (re)design: More attention is paid to organizational (re)design (from 8 to 16 studies).

Although the number of studies on this subject has increased, there still remains unclarity about its effects because of the variation in interventions and the mixed nature of the results.

- Programmes: There seems to be new focus on a programmatic approach in which training, tools, and/or organizational (re)design are combined, often focused around the topic patient safety. The previous review identified only one such study; this research found 24 studies, not including the CRM studies for which some also use a more programmatic approach. There seems to be stronger evidence that this approach of combining interventions may be effective in improving teamwork.

\section{Limitations}

The main limitation of this review is that we cannot claim that we have found every single study per subcategory. This would have required per subcategory an additional systematic review or an umbrella review, using additional keywords. As we identified a variety of literature reviews, future research should focus on umbrella reviews in addition to new systematic literature reviews. Note that we did find more studies per subcategory, but they did not meet our inclusion criteria. For example, we excluded multiple studies evaluating surgical checklists that did not measure its effect on team functioning but only on reported errors or morbidity. Although this review presents all relevant categories to improve team functioning in healthcare organizations, those categories are limited to team literature and are not based on related research fields such as integrated care and network medicine. Another limitation is that we excluded grey literature by only focusing on articles written in English that present empirical data and were published in peerreviewed journals. Consequently, we might have excluded studies that present negative or non-significant effects of team interventions, and such an exclusion is also known as publication bias. In addition, the combination of the publication bias and the exclusion of grey literature has probably resulted in a main focus on standardized interventions and a limited range of alternative approaches, which does not necessarily reflect practice.

\section{Implication for future research}

This review shows the major increase in the last decade in the number of studies on how to improve team functioning in healthcare organizations. At the same time, it 
shows that this research tends to focus around certain interventions, settings, and outcomes. This helped to provide more evidence but also left four major gaps in the current literature. First, less evidence is available about interventions to improve team functioning outside the hospital setting (e.g. primary care, youth care, mental health care, care for disabled people). With the worldwide trend to provide more care at home, this is an important gap. Thereby, team characteristics across healthcare settings vary significantly, which challenges the generalizability [327]. Second, little is known about the long-term effects of the implemented interventions. We call for more research that monitors the effects over a longer period of time and provides insights into factors that influence their sustainability. Third, studies often provide too little information about the context. To truly understand why a team intervention affects performance and to be able to replicate the effect (by researchers and practitioners), detailed information is required related to the implementation process of the intervention and the context. Fourth, the total picture of relevant outcomes is missing. We encourage research that includes less frequently used outcomes such as well-being of professionals and focuses on identifying possible deadly combinations between outcomes.

\section{Supplementary information}

Supplementary information accompanies this paper at https://doi.org/10. 1186/s12960-019-0411-3.

Additional file 1. Search syntax EMBASE (DOCX $12 \mathrm{~kb}$ )

Additional file 2. GRADE (DOCX $13 \mathrm{~kb})$

\begin{abstract}
Abbreviations
AHRQ: Agency for Healthcare Research and Quality; CRM: Crew resource management; CUSP: Comprehensive Unit-Based Safety Program; DoD: Department of Defense; GRADE: Grading of Recommendations Assessment Development, and Evaluation; MTT: Medical team training; NOTECHS: Non-Technical Skills; PRISMA: Preferred Reporting Items for Systematic Reviews and Meta-Analyses; SAQ: Safety Attitude Questionnaire; SBAR: Situation, Background, Assessment, and Recommendation; SSC: Surgical safety checklist; TeamSTEPPS: Team Strategies and Tools to Enhance Performance and Patient Safety
\end{abstract}

\section{Acknowledgements}

We would like to thank Wichor Bramer, Librarian at the Erasmus Medical Center Rotterdam, The Netherlands, for his support in conducting the search for this systematic review.

\section{Authors' contributions}

MBS, KDD, and JDHW reviewed titles, abstracts, and full texts for the systematic review. MBS initiated the first draft of the manuscript and revised the manuscript on the basis of input of KDD and JDHW. MBS, KDD, and JDHW together categorized the results. All authors read and approved the final manuscript.

\section{Funding}

This research received no specific grant from any funding agency in the public, commercial, or not-for-profit sectors.
Availability of data and materials

Not applicable

Ethics approval and consent to participate

Not applicable

\section{Consent for publication}

Not applicable

\section{Competing interests}

The authors declare that they have no competing interests.

\section{Author details}

${ }^{1}$ Erasmus School of Health Policy \& Management, Erasmus University Rotterdam, Bayle building, p.o. box 1738, 3000, DR, Rotterdam, The Netherlands. ${ }^{2}$ Erasmus School of Health Policy \& Management, Erasmus University Rotterdam, Bayle building, p.o. box 1738, 3000, DR, Rotterdam, The Netherlands. ${ }^{3}$ Erasmus School of Health Policy \& Management, Erasmus University Rotterdam, Bayle building, p.o. box 1738, 3000, DR, Rotterdam, The Netherlands.

Received: 14 January 2019 Accepted: 5 September 2019

Published online: 08 January 2020

References

1. Donaldson MS, Corrigan JM, Kohn LT. To err is human: building a safer health system: National Academies Press; 2000.

2. Manser T. Teamwork and patient safety in dynamic domains of healthcare: a review of the literature. Acta Anaesthesiol Scand. 2009:53:143-51.

3. Hughes AM, Gregory ME, Joseph DL, Sonesh SC, Marlow SL, Lacerenza CN, et al. Saving lives: a meta-analysis of team training in healthcare. J Appl Psychol. 2016;101:1266-304.

4. Murphy $\mathrm{M}$, Curtis $\mathrm{K}, \mathrm{McCloughen} \mathrm{A}$. What is the impact of multidisciplinary team simulation training on team performance and efficiency of patient care? An integrative review. Australasian Emerg Nurs J. 2016;19(1):44-53.

5. Neily J, Mills PD, Young-Xu Y, Carney BT, West P, Berger DH, et al. Association between implementation of a medical team training program and surgical mortality. J Am Med Assoc. 2010;304:1693-700.

6. Salas E, Klein C, King H, Salisbury M, Augenstein JS, Birnbach DJ, et al. Debriefing medical teams: 12 evidence-based best practices and tips. Jt Comm J Qual Patient Saf. 2008;34:518-27.

7. Tan SB, Pena G, Altree M, Maddern GJ. Multidisciplinary team simulation for the operating theatre: a review of the literature. ANZ J Surg. 2014;84(7-8): 515-22.

8. Buljac-Samardzic M, Dekker-van Doorn CM, Van Wijngaarden JDH, Van Wijk KP. Interventions to improve team effectiveness: a systematic review. Health Policy. 2010;94(3):183-95.

9. O'Dea A, O'Connor P, Keogh I. A meta-analysis of the effectiveness of crew resource management training in acute care domains. Postgrad Med J. 2014;90:699-708.

10. Maynard MT, Marshall D, Dean MD. Crew resource management and teamwork training in health care: a review of the literature and recommendations for how to leverage such interventions to enhance patient safety. Adv Health Care Manag. 2012;13:59-91.

11. Verbeek-van Noord I, de Bruijne MC, Zwijnenberg NC, Jansma EP, van Dyck C, Wagner C. Does classroom-based crew resource management training improve patient safety culture? A systematic review. SAGE open medicine. 2014;2:2050312114529561.

12. Boet S, Bould MD, Fung L, Qosa H, Perrier L, Tavares W, et al. Transfer of learning and patient outcome in simulated crisis resource management: a systematic review. Canadian Journal of Anesthesia/Journal canadien d'anesthésie. 2014:61(6):571-82.

13. Fung $L$, Boet $S$, Bould MD, Qosa $H$, Perrier $L$, Tricco A, et al. Impact of crisis resource management simulation-based training for interprofessional and interdisciplinary teams: a systematic review. J Interprof Care. 2015;29(5):433-44.

14. Doumouras AG, Keshet I, Nathens AB, Ahmed N, Hicks CM. A crisis of faith? A review of simulation in teaching team-based, crisis management skills to surgical trainees. J Surg Educ. 2012;69(3):274-81. 
15. Weaver SJ, Rosen MA, DiazGranados D, Lazzara EH, Lyons R, Salas E, et al. Does teamwork improve performance in the operating room? A multilevel evaluation. Jt Comm J Qual Patient Saf. 2010;36:133-42.

16. McCulloch P, Rathbone J, Catchpole K. Interventions to improve teamwork and communications among healthcare staff. Br J Surg. 2011 98(4):469-79.

17. Carne B, Kennedy M, Gray T. Review article: crisis resource management in emergency medicine. EMA Emerg Med Australas. 2012;24:7-13.

18. Russ S, Rout S, Sevdalis N, Moorthy K, Darzi A, Vincent C. Do safety checklists improve teamwork and communication in the operating room? A systematic review. Ann Surg. 2013;258:856-71.

19. Sacks GD, Shannon EM, Dawes AJ, Rollo JC, Nguyen DK, Russell MM, et al. Teamwork, communication and safety climate: a systematic review of interventions to improve surgical culture. BMJ Qual Saf. 2015;24:458-67.

20. Weaver SJ, Dy SM, Rosen MA. Team-training in healthcare: a narrative synthesis of the literature. BMJ Qual Saf. 2014;23(5):359-72.

21. Shields A, Flin R. Paramedics' non-technical skills: a literature review. Emerg Med J. 2013;30(5):350-4.

22. McEwan D, Ruissen GR, Eys MA, Zumbo BD, Beauchamp MR. The effectiveness of teamwork training on teamwork behaviors and team performance: a systematic review and meta-analysis of controlled interventions. PloS one. 2017;12(1):e0169604.

23. Borchard A, Schwappach DLB, Barbir A, Bezzola P. A systematic review of the effectiveness, compliance, and critical factors for implementation of safety checklists in surgery. Ann Surg. 2012 Dec;256:925-33.

24. Robertson JM, Dias RD, Yule S, Smink DS. Operating room team training with simulation: a systematic review. J Laparoendosc Adv Surg Tech A. 2017;27(5):475-80.

25. Cunningham U, Ward M, De Brún A, McAuliffe E. Team interventions in acute hospital contexts: a systematic search of the literature using realist synthesis. BMC health services research. 2018;18(1):536.

26. Cheng A, Eppich W, Grant V, Sherbino J, Zendejas B, Cook DA. Debriefing for technology-enhanced simulation: a systematic review and meta-analysis. Med Educ. 2014;48(7):657-66.

27. Gordon M, Findley R. Educational interventions to improve handover in health care: a systematic review. Med Educ. 2011;45:1081-9.

28. Reeves S, Perrier L, Goldman J, Freeth D, Zwarenstein M. Interprofessional education: effects on professional practice and healthcare outcomes (update). Cochrane Database Syst Rev. 2013;(3):3.

29. Allan CK, Thiagarajan RR, Beke D, Imprescia A, Kappus LJ, Garden A, et al. Simulation-based training delivered directly to the pediatric cardiac intensive care unit engenders preparedness, comfort, and decreased anxiety among multidisciplinary resuscitation teams. J Thorac Cardiovasc Surg. 2010; 140:646-52.

30. Ballangrud R, Hall-Lord M, Persenius M, Hedelin B. Intensive care nurses' perceptions of simulation-based team training for building patient safety in intensive care: a descriptive qualitative study. Intensive Crit Care Nurs. 2014; 30:179-87.

31. Bank I, Snell L, Bhanji F. Pediatric crisis resource management training improves emergency medicine trainees' perceived ability to manage emergencies and ability to identify teamwork errors. Pediatr Emerg Care. 2014;30:879-83.

32. Budin WC, Gennaro S, O'Connor C, Contratti F. Sustainability of improvements in perinatal teamwork and safety climate. J Nurs Care Qual. 2014:29:363-70

33. Carbo AR, Tess AV, Roy C, Weingart SN. Developing a high-performance team training framework for internal medicine residents: the ABC'S of teamwork. J Patient Saf. 2011;7:72-6.

34. Catchpole KR, Dale TJ, Hirst DG, Smith JP, Giddings TA. A multicenter trial of aviation-style training for surgical teams. J Patient Saf. 2010;6:180-6.

35. Clay-Williams R, McIntosh CA, Kerridge R, Braithwaite J. Classroom and simulation team training: a randomized controlled trial. Int J Qual Health Care. 2013;25:314-21.

36. Cooper JB, Blum RH, Carroll JS, Dershwitz M, Feinstein DM, Gaba DM, et al. Differences in safety climate among hospital anesthesia departments and the effect of a realistic simulation-based training program. Anesth Analg. 2008; 106:574-84

37. France DJ, Leming-Lee S, Jackson T, Feistritzer NR, Higgins MS. An observational analysis of surgical team compliance with perioperative safety practices after crew resource management training. Am J Surg. 2008;195: 546-53.
38. Gardner R, Walzer TB, Simon R, Raemer DB. Obstetric simulation as a risk control strategy: course design and evaluation. Simul Healthc. 2008;3:119-27.

39. Gore DC, Powell JM, Baer JG, Sexton KH. Crew resource management improved perception of patient safety in the operating room. Am J Med Qual. 2010;25(1):60-3.

40. Haerkens MHTM, Kox M, Noe PM, van dH, Pickkers P. Crew resource management in the trauma room: a prospective 3-year cohort study. Eur J Emerg Med. 2017.

41. Haller G, Garnerin P, Morales MA, Pfister R, Berner M, Irion O, et al. Effect of crew resource management training in a multidisciplinary obstetrical setting. Int J Qual Health Care. 2008;20:254-63.

42. Hefner JL, Hilligoss B, Knupp A, Bournique J, Sullivan J, Adkins E, et al. Cultural transformation after implementation of Crew Resource Management: is it really possible? Am J Med Qual. 2017;32:384-90.

43. Hicks CM, Kiss A, Bandiera GW, Denny CJ. Crisis Resources for Emergency Workers (CREW II): results of a pilot study and simulation-based crisis resource management course for emergency medicine residents. Can J Emerg Med. 2012;14:354-62.

44. Hughes KM, Benenson RS, Krichten AE, Clancy KD, Ryan JP, Hammond C. A crew resource management program tailored to trauma resuscitation improves team behavior and communication. J Am Coll Surg. 2014;219:545-51.

45. de Korne DF, van Wijngaarden JDH, van Dyck C, Hiddema UF, Klazinga NS. Evaluation of aviation-based safety team training in a hospital in The Netherlands. J.Health Organ.Manag. 2014;28:731-53.

46. Kuy S, Romero RAL. Improving staff perception of a safety climate with crew resource management training. J Surg Res. 2017;213:177-83.

47. LaPoint $\mathrm{J}$. The effects of aviation error management training on perioperative safety attitudes. Intern J Business and Soc Sci. 2012;3:2.

48. Mahramus TL, Penoyer DA, Waterval EM, Sole ML, Bowe EM. Two Hours of Teamwork Training Improves Teamwork in Simulated Cardiopulmonary Arrest Events. Clin Nurse Spec. 2016;30:284-91.

49. McCulloch P, Mishra A, Handa A, Dale T, Hirst G, Catchpole K. The effects of aviation-style non-technical skills training on technical performance and outcome in the operating theatre. Qual Saf Health Care. 2009;18:109-15.

50. Mehta N, Boynton C, Boss L, Morris H, Tatla T. Multidisciplinary difficult airway simulation training: two year evaluation and validation of a novel training approach at a District General Hospital based in the UK. Eur Arch Oto-Rhino-Laryngol. 2013;270:211-7.

51. Morgan L, Pickering SP, Hadi M, Robertson E, New S, Griffin D, et al. A combined teamwork training and work standardisation intervention in operating theatres: controlled interrupted time series study. BMJ Qual Saf. 2015:24:111-9.

52. Morgan L, Hadi M, Pickering S, Robertson E, Griffin D, Collins G, et al. The effect of teamwork training on team performance and clinical outcome in elective orthopaedic surgery: a controlled interrupted time series study. BMJ Open. 2015;5.

53. Müller MP, Hänsel M, Fichtner A, Hardt F, Weber S, Kirschbaum C, et al. Excellence in performance and stress reduction during two different full scale simulator training courses: a pilot study. Resuscitation. 2009;80(8):919-24.

54. Parsons JR, Crichlow A, Ponnuru S, Shewokis PA, Goswami V, Griswold S. Filling the gap: simulation-based crisis resource management training for emergency medicine residents. West J Emerg Med. 2018;19:205-10.

55. Phipps MG, Lindquist DG, McConaughey E, O'Brien JA, Raker CA, Paglia MJ. Outcomes from a labor and delivery team training program with simulation component. Obstet Gynecol. 2012;206:3-9.

56. Ricci MA, Brumsted JR. Crew resource management: using aviation techniques to improve operating room safety. Aviat Space Environ Med. 2012;83(4):441-4.

57. Robertson B, Schumacher L, Gosman G, Kanfer R, Kelley M, DeVita M. Simulation-based crisis team training for multidisciplinary obstetric providers. Simul Healthc. 2009:4:77-83.

58. Savage C, Andrew Gaffney F, Hussainalkhateeb L, Ackheim PO, Henricson G, Antoniadou I, et al. Safer paediatric surgical teams: a 5-year evaluation of crew resource management implementation and outcomes. Int I Qual Health Care. 2017;29:853-60

59. Sax HC, Browne P, Mayewski RJ. Can aviation-based team training elicit sustainable behavioral change?: archopht.jamanetwork.com; 2009.

60. Shea-Lewis A. Teamwork: crew resource management in a community hospital. J Healthc Qual. 2009;31:14-8.

61. Schwartz ME, Welsh DE, Paull DE, Knowles RS, DeLeeuw LD, Hemphill RR, et al. The effects of crew resource management on teamwork and safety climate at Veterans Health Administration facilities. 2017. 
62. Sculli GL, Fore AM, West P, Neily J, Mills PD, Paull DE. Nursing crew resource management a follow-up report from the Veterans Health Administration. J Nurs Adm. 2013;43:122-6.

63. Steinemann S, Berg B, Skinner A, Ditulio A, Anzelon K, Terada K, et al. In situ, multidisciplinary, simulation-based teamwork training improves early trauma care. J Surg Educ. 2011;68:472-7.

64. Stevens LM, Cooper JB, Raemer DB, Schneider RC, Frankel AS, Berry WR, et al. Educational program in crisis management for cardiac surgery teams including high realism simulation. J Thorac Cardiovasc Surg. 2012;144:17-24.

65. Suva $D$, Haller $G, L \tilde{A} 1 / 4$ bbeke A, Hoffmeyer P. Differential impact of a crew resource management program according to professional specialty. Am J Med Qual 2012;27:313-320.

66. Tschannen D, McClish D, Aebersold M, Rohde JM. Targeted communication intervention using nursing crew resource management principles. J Nurs Care Qual. 2015;30(1):7-11.

67. West P, Sculli G, Fore A, Okam N, Dunlap C, Neily J, et al. Improving patient safety and optimizing nursing teamwork using crew resource management techniques. J Nurs Adm. 2012;42:15-20.

68. Ziesmann MT, Widder S, Park J, Kortbeek JB, Brindley P, Hameed M, et al. S. T.A.R.T.T.: development of a national, multidisciplinary trauma crisis resource management curriculum-results from the pilot course. J Trauma Acute Care Surg. 2013;75:753-8.

69. Forse RA, Bramble JD, McQuillan R. Team training can improve operating room performance. Surgery (USA). 2011;150:771-8.

70. Bridges $R$, Sherwood G, Durham C. Measuring the influence of a mutual support educational intervention within a nursing team. Int J Nurs Sci. 2014; 1:15-22.

71. Brodsky D, Gupta M, Quinn M, Smallcomb J, Mao W, Koyama N, et al. Building collaborative teams in neonatal intensive care. BMJ Qual Saf. 2013; 22:374-82.

72. Bui AH, Guerrier S, Feldman DL, Kischak P, Mudiraj S, Somerville D, et al. Is video observation as effective as live observation in improving teamwork in the operating room? Surgery. 2018;163:1191-6.

73. Capella J, Smith S, Philp A, Putnam T, Gilbert C, Fry W, et al. Teamwork training improves the clinical care of trauma patients. J Surg Educ. 2010;67: 439-43.

74. Castner J, Foltz-Ramos K, Schwartz DG, Ceravolo DJ. A leadership challenge: staff nurse perceptions after an organizational TeamSTEPPS initiative. J Nurs Adm. 2012;42:467-72.

75. Deering S, Johnston LC, Colacchio K. Multidisciplinary teamwork and communication training. Semin Perinatol. 2011;35:89-96.

76. Figueroa MI, Sepanski R, Goldberg SP, Shah S. Improving teamwork, confidence, and collaboration among members of a pediatric cardiovascular intensive care unit multidisciplinary team using simulation-based team training. Pediatr Cardiol. 2013;34:612-9.

77. Gaston T, Short N, Ralyea C, Casterline G. Promoting patient safety results of a TeamSTEPPS (R) initiative. J Nurs Adm. 2016;46:201-7.

78. Gupta RT, Sexton JB, Milne J, Frush DP. Practice and quality improvement: successful implementation of TeamSTEPPS tools into an academic interventional ultrasound practice. Am J Roentgenol. 2015;204:105-10.

79. Harvey EM, Echols SR, Clark R, Lee E. Comparison of two TeamSTEPPS (R) training methods on nurse failure-to-rescue performance. Clin.Simul.Nurs. 2014;10:E57-64.

80. Jones KJ, Skinner AM, High R. A theory-driven, longitudinal evaluation of the impact of team training on safety culture in 24 hospitals. BMJ quality and safety. 2013.

81. Jones F, Podila P, Powers C. Creating a culture of safety in the emergency department: the value of teamwork training. J Nurs Adm. 2013;43:194-200

82. Lee SH, Khanuja HS, Blanding RJ, Sedgwick J, Pressimone K, Ficke JR, et al. Sustaining teamwork behaviors through reinforcement of TeamSTEPPS principles. J Patient Saf. 2017.

83. Lisbon D, Allin D, Cleek C, Roop L, Brimacombe M, Downes C, et al. Improved knowledge, attitudes, and behaviors after implementation of TeamSTEPPS training in an academic emergency department: A Pilot Report. Am J Med Qual. 2016;31:86-90.

84. Mahoney JS, Ellis TE, Garland G, Palyo N, Greene PK. Supporting a psychiatric hospital culture of safety. J Am Psychiatr Nurs Assoc. 2012;18: 299-306.

85. Mayer CM, Cluff L, Lin WT, Willis TS, Stafford RE, Williams C, et al. Evaluating efforts to optimize TeamSTEPPS implementation in surgical and pediatric intensive care units. Jt Comm J Qual Patient Saf. 2011;37:365-74.
86. Rice Y, DeLetter M, Fryman L, Parrish E, Velotta C, Talley C. Implementation and evaluation of a team simulation training program. J Trauma Nurs. 2016; 23:298-303

87. Riley W, Davis S, Miller K, Hansen H, Sainfort F, Sweet R. Didactic and simulation nontechnical skills team training to improve perinatal patient outcomes in a community hospital. Jt Comm J Qual Patient Saf. 2011;37:357-64.

88. Sawyer T, Laubach VA, Hudak J, Yamamura K, Pocrnich A. Improvements in teamwork during neonatal resuscitation after interprofessional TeamSTEPPS training. Neonatal Netw. 2013;32:26-33.

89. Sonesh SC, Gregory ME, Hughes AM, Feitosa J, Benishek LE, Verhoeven D, et al. Team training in obstetrics: a multi-level evaluation. Fam Syst Health. 2015;33:250-61.

90. Spiva L, Robertson B, Delk ML, Patrick S, Kimrey MM, Green B, et al. Effectiveness of team training on fall prevention. J Nurs Care Qual. 2014;29: 164-73.

91. Stead K, Kumar S, Schultz TJ, Tiver S, Pirone CJ, Adams RJ, et al. Teams communicating through STEPPS. Med J Aust. 2009;190:S128-32.

92. Thomas L, Galla C. Building a culture of safety through team training and engagement. BMJ Qual Saf. 2013;22:425-34

93. Treadwell J, Binder B, Symes L, Krepper R. Delivering team training to medical home staff to impact perceptions of collaboration. Professional case management. 2015;20(2):81-8.

94. Vertino KA. Evaluation of a TeamSTEPPS@ initiative on staff attitudes toward teamwork. J Nurs Adm. 2014;44:97-102.

95. Wong AH, Gang M, Szyld D, Mahoney H. Making an "attitude adjustment": using a simulation-enhanced interprofessional education strategy to improve attitudes toward teamwork and communication. Simul.healthc. 2016;11:117-25.

96. AbdelFattah KR, Spalding MC, Leshikar D, Gardner AK. Team-based simulations for new surgeons: does early and often make a difference? Surgery. 2018;163:912-5.

97. Amiel I, Simon D, Merin O, Ziv A. Mobile in situ simulation as a tool for evaluation and improvement of trauma treatment in the emergency department. J Surg Educ. 2016;73:121-8.

98. Arora S, Cox C, Davies S, Kassab E, Mahoney P, Sharma E, et al. Towards the next frontier for simulation-based training: full-hospital simulation across the entire patient pathway. Ann Surg. 2014;260(2):252-8.

99. Arora S, Hull L, Fitzpatrick M, Sevdalis N, Birnbach DJ. Crisis management on surgical wards: a simulation-based approach to enhancing technical, teamwork, and patient interaction skills. Ann Surg. 2015;261:888-93.

100. Artyomenko W, Nosenko VM. Anaesthesiologists' simulation training during emergencies in obstetrics. Romanian J Anaesth Intensive Care. 2017;24:37-40.

101. Auerbach M, Roney L, Aysseh A, Gawel M, Koziel J, Barre K, et al. In situ pediatric trauma simulation: assessing the impact and feasibility of an interdisciplinary pediatric in situ trauma care quality improvement simulation program. Pediatr Emerg Care. 2014;30:884-91.

102. Bender J, Kennally K, Shields R, Overly F. Does simulation booster impact retention of resuscitation procedural skills and teamwork. J Perinatol. 2014; 34:664-8.

103. Bittencourt T, Kerrey BT, Taylor RG, FitzGerald M, Geis GL. Teamwork skills in actual, in situ, and in-center pediatric emergencies performance levels across settings and perceptions of comparative educational impact. Simul. Healthc. 2015;10:76-84.

104. Bruppacher HR, Alam SK, Leblanc VR, Latter D, Naik VN, Savoldelli GL, et al. Simulation-based training improves physicians performance in patient care in high-stakes clinical setting of cardiac surgery. Anesthesiology. 2010;112: 985-92.

105. Bursiek AA, Hopkins MR, Breitkopf DM, Grubbs PL, Joswiak ME, Klipfel JM, et al. Use of high-fidelity simulation to enhance interdisciplinary collaboration and reduce patient falls. J Patient Saf. 2017;07.

106. Burton KS, Pendergrass TL, Byczkowski TL, Taylor RG, Moyer MR, Falcone RA, et al. Impact of simulation-based extracorporeal membrane oxygenation training in the simulation laboratory and clinical environment. Simul Healthc. 2011;6:284-91.

107. Chung SP, Cho J, Park YS, Kang HG, Kim CW, Song KJ, et al. Effects of scriptbased role play in cardiopulmonary resuscitation team training. Emergency Medicine Journal. 2011;28(8):690-4.

108. Cooper S, Cant R, Porter J, Missen K, Sparkes L, McConnell-Henry T, et al. Managing patient deterioration: assessing teamwork and individual performance. Emerg Med J. 2013;30:377-81. 
109. Ciporen J, Gillham H, Noles M, Dillman D, Baskerville M, Haley C, et al. Crisis management simulation: establishing a dual neurosurgery and anesthesia training experience. J Neurosurg Anesthesiol. 2018;30:65-70.

110. Ellis D, Crofts JF, Hunt LP, Read M, Fox R, James M. Hospital, simulation center, and teamwork training for eclampsia management: a randomized controlled trial. Obstet Gynecol. 2008;111:723-31.

111. Fernando A, Attoe C, Jaye P, Cross S, Pathan J, Wessely S. Improving interprofessional approaches to physical and psychiatric comorbidities through simulation. Clin.Simul.Nurs. 2017;13:186-93.

112. Fouilloux V, Gsell T, Lebel S, Kreitmann B, Berdah S. Assessment of team training in management of adverse acute events occurring during cardiopulmonary bypass procedure: a pilot study based on an animal simulation model (Fouilloux, Team training in cardiac surgery). Perfusion. 2014;29:44-52.

113. Fransen AF, Ven VD, AER MÃ@n, De Wit-Zuurendonk LD, Houterman S, Mol BW, et al. Effect of obstetric team training on team performance and medical technical skills: a randomised controlled trial. BJOG Int J Obstet Gynaecol. 2012;119:1387-93.

114. Freeth D, Ayida G, Berridge EJ, Mackintosh N, Norris B, Sadler C, et al. Multidisciplinary obstetric simulated emergency scenarios (MOSES): promoting patient safety in obstetrics with teamwork-focused interprofessional simulations. J Contin Educ Health Prof. 2009;29:98-104.

115. Frengley RW, Weller JM, Torrie J, Dzendrowskyj P, Yee B, Paul AM, et al. The effect of a simulation-based training intervention on the performance of established critical care unit teams. Crit Care Med. 2011;39:2605-11.

116. George KL, Quatrara B. Interprofessional simulations promote knowledge retention and enhance perceptions of teamwork skills in a surgical-traumaburn intensive care unit setting. Dccn. 2018;37:144-55.

117. Gettman MT, Pereira CW, Lipsky K, Wilson T, Arnold JJ, Leibovich BC, et al. Use of high fidelity operating room simulation to assess and teach communication, teamwork and laparoscopic skills: initial experience. J Urol. 2009:181:1289-96.

118. Gilfoyle E, Koot DA, Annear JC, Bhanji F, Cheng A, Duff JP, et al. Improved clinical performance and teamwork of pediatric interprofessional resuscitation teams with a simulation-based educational intervention. Pediatr Crit Care Med. 2017:18:e62-9.

119. Gum L, Greenhill J, Dix K. Clinical simulation in maternity (CSiM): interprofessional learning through simulation team training. Qual Saf Health Care. 2010;19:e19.

120. Hamilton NA, Kieninger AN, Woodhouse J, Freeman BD, Murray D, Klingensmith ME. Video review using a reliable evaluation metric improves team function in high-fidelity simulated trauma resuscitation. J Surg Educ. 2012;69:428-31.

121. Hoang TN, Kang J, Siriratsivawong K, LaPorta A, Heck A, Ferraro J, et al. Hyper-realistic, team-centered fleet surgical team training provides sustained improvements in performance. J Surg Educ. 2016;73:668-74.

122. James TA, Page JS, Sprague J. Promoting interprofessional collaboration in oncology through a teamwork skills simulation programme. J Interprof Care. 2016;7:1-3.

123. Kalisch BJ, Gosselin K, Choi SH. A comparison of patient care units with high versus low levels of missed nursing care. Health Care Manage Rev. 2012;37: 320-8.

124. Khobrani A, Patel NH, George RL, McNinch NL, Ahmed RA. Pediatric trauma boot camp: a simulation curriculum and pilot study. Emerg.Med.Int. 2018.

125. Kilday D, Spiva L, Barnett J, Parker C, Hart P. The effectiveness of combined training modalities on neonatal rapid response teams. Clin.Simul.Nurs. 2013; 9:E249-56.

126. Kirschbaum KA, Rask JP, Brennan M, Phelan S, Fortner SA. Improved climate, culture, and communication through multidisciplinary training and instruction. Obstet Gynecol. 2012;207:200.e1-7.

127. Koutantji M, McCulloch P, Undre S, Gautama S, Cunniffe S, Sevdalis N, et al. Is team training in briefings for surgical teams feasible in simulation? Cognition, Technology \& Work. 2008;10(4):275-85.

128. Kumar A, Sturrock S, Wallace EM, Nestel D, Lucey D, Stoyles S, et al. Evaluation of learning from Practical Obstetric Multi-Professional Training and its impact on patient outcomes in Australia using Kirkpatrick's framework: a mixed methods study. BMJ Open. 2018;17(8):e017451.

129. Larkin AC, Cahan MA, Whalen G, Hatem D, Starr S, Haley HL, et al. Human emotion and response in surgery (HEARS): a simulation-based curriculum for communication skills, systems-based practice, and professionalism in surgical residency training. J Am Coll Surg. 2010;211:285-92.
130. Lavelle M, Abthorpe J, Simpson T, Reedy G, Little F, Banerjee A. MBRRACE in simulation: an evaluation of a multi-disciplinary simulation training for medical emergencies in obstetrics (MEmO). J Obstet Gynaecol. 2018:1-8.

131. Lavelle M, Attoe C, Tritschler C, Cross S. Managing medical emergencies in mental health settings using an interprofessional in-situ simulation training programme: a mixed methods evaluation study. Nurse Educ Today. 2017:59: 103-9.

132. Lee JY, Mucksavage P, Canales C, McDougall EM, Lin S. High fidelity simulation based team training in urology: a preliminary interdisciplinary study of technical and nontechnical skills in laparoscopic complications management. J Urol. 2012;187(4):1385-91.

133. Lorello GR, Hicks CM, Ahmed SA, Unger Z, Chandra D, Hayter MA. Mental practice: a simple tool to enhance team-based trauma resuscitation. Can J Emerg Med. 2016;18:136-42.

134. Mager DR, Lange JW, Greiner PA, Saracino KH. Using simulation pedagogy to enhance teamwork and communication in the care of older adults: the ELDER project. J Contin Educ Nurs. 2012;43:363-9.

135. Maxson PM, Dozois EJ, Holubar SD, Wrobleski DM, Dube JAO, Klipfel JM et al. Enhancing nurse and physician collaboration in clinical decision making through high-fidelity interdisciplinary simulation training. Mayo Clin Proc. 2011:86:31-6.

136. McLaughlin T, Hennecke P, Garraway NR, Evans DC, Hameed M, Simons RK, et al. A predeployment trauma team training course creates confidence in teamwork and clinical skills: a post-Afghanistan deployment validation study of Canadian Forces healthcare personnel. Journal of Trauma and Acute Care Surgery. 2011;71(5):487-93.

137. Meurling L, Hedman L. Fellãander-Tsai L, Wallin CJ. Leaders' and followers' individual experiences during the early phase of simulation-based team training: an exploratory study. BMJ Qual Saf. 2013;22:459-67.

138. Miller D, Crandall C, Washington lii C, McLaughlin S. Improving teamwork and communication in trauma care through in situ simulations. Acad Emerg Med. 2012;19:608-12.

139. van der Nelson SD, Bennett J, Godfrey M, Spray L, Draycott T, et al. Multiprofessional team simulation training, based on an obstetric model, can improve teamwork in other areas of health care. Am J Med Qual. 2014; 29:78-82.

140. Nicksa GA, Anderson C, Fidler R, Stewart L. Innovative approach using interprofessional simulation to educate surgical residents in technical and nontechnical skills in high-risk clinical scenarios. JAMA Surg. 2015;150:201-7.

141. Niell BL, Kattapuram T, Halpern EF, Salazar GM, Penzias A, Bonk SS, et al. Prospective analysis of an interprofessional team training program using highfidelity simulation of contrast reactions. Am J Roentgenol. 2015;204:W670-6.

142. Oseni Z, Than HH, Kolakowska E, Chalmers L, Hanboonkunupakarn B, McGready R. Video-based feedback as a method for training rural healthcare workers to manage medical emergencies: a pilot study. BMC Med Educ. 2017;17:149.

143. Paige JT, Kozmenko V, Yang T, Gururaja RP, Hilton CW, Cohn I Jr, et al. Attitudinal changes resulting from repetitive training of operating room personnel using high-fidelity simulation at the point of care. Am Surg. 2009:75:584-90.

144. Paltved C, Bjerregaard AT, Krogh K, Pedersen JJ, Musaeus P. Designing in situ simulation in the emergency department: evaluating safety attitudes amongst physicians and nurses. Adv Simul (Lond). 2017;2:4.

145. Pascual JL, Holena DN, Vella MA, Palmieri J, Sicoutris C, Selvan B, et al. Short simulation training improves objective skills in established advanced practitioners managing emergencies on the ward and surgical intensive care unit. J Trauma Inj Infect Crit Care. 2011;71:330-8.

146. Patterson MD, Geis GL, Falcone RA. In situ simulation: detection of safety threats and teamwork training in a high risk emergency department. BMJ Qual Saf. 2013;22(6):468-77.

147. Patterson MD, Geis GL, LeMaster T, Wears RL. Impact of multidisciplinary simulation-based training on patient safety in a paediatric emergency department. BMJ Qual Saf. 2013:22:383-93.

148. Pennington KM, Dong Y, Coville HH, Wang B, Gajic O, Kelm DJ. Evaluation of TEAM dynamics before and after remote simulation training utilizing CERTAIN platform. Med.educ.online. 2018;23:1485431.

149. Rao R, Dumon KR, Neylan CJ, Morris JB, Riddle EW, Sensenig R, et al. Can simulated team tasks be used to improve nontechnical skills in the operating room? J Surg Educ. 2016;73:e42-7.

150. Reynolds A, Ayres-De-Campos D, Lobo M. Self-perceived impact of simulation-based training on the management of real-life obstetrical emergencies. Eur J Obstet Gynecol Reprod Biol. 2011;159:72-6. 
151. Roberts NK, Williams RG, Schwind CJ, Sutyak JA, McDowell C, Griffen D, et al. The impact of brief team communication, leadership and team behavior training on ad hoc team performance in trauma care settings. Am J Surg. 2014;207:170-8

152. Rubio-Gurung S, Putet G, Touzet S, Gauthier-Moulinier H, Jordan I, Beissel A, et al. In situ simulation training for neonatal resuscitation: an RCT. Pediatrics. 2014;134:e790-7.

153. Sandahl C, Gustafsson H, Wallin CJ, Meurling L, Ã̃retveit J, Brommels M, et al. Simulation team training for improved teamwork in an intensive care unit. Int J Health Care Qual Assur. 2013;26:174-88.

154. Shoushtarian M, Barnett M, McMahon F, Ferris J. Impact of introducing Practical Obstetric Multi-Professional Training (PROMPT) into maternity units in Victoria, Australia. BJOG Int J Obstet Gynaecol. 2014;121:1710-8.

155. Siassakos D, Fox R, Hunt L, Farey J, Laxton C, Winter C, et al. Attitudes toward safety and teamwork in a maternity unit with embedded team training. Am J Med Qual. 2011;26:132-7.

156. Siassakos D, Hasafa Z, Sibanda T, Fox R, Donald F, Winter C, et al. Retrospective cohort study of diagnosis-delivery interval with umbilical cord prolapse: the effect of team training. BJOG Int J Obstet Gynaecol. 2009;116:1089-96.

157. Silberman NJ, Mintz SB, Zych N, Bloch N, Tal ER, Rios L. Simulation training facilitates physical therapists' self-efficacy in the intensive care unit. J Acute Care Phys Ther. 2018;9:47-59.

158. Stewart-Parker E, Galloway R, Vig S. S-TEAMS: a truly multiprofessional course focusing on nontechnical skills to improve patient safety in the operating theater. J Surg Educ. 2017;74:137-44.

159. Stocker M, Allen M, Pool N, De Costa K, Combes J, West N, et al. Impact of an embedded simulation team training programme in a paediatric intensive care unit: a prospective, single-centre, longitudinal study. Intensive Care Med. 2012;38:99-104.

160. Sudikoff SN, Overly FL, Shapiro MJ. High-fidelity medical simulation as a technique to improve pediatric residents' emergency airway management and teamwork: a pilot study. Pediatr Emerg Care. 2009;25: 651-6.

161. Thomas EJ, Williams AL, Reichman EF, Lasky RE, Crandell S, Taggarte WR. Team training in the Neonatal Resuscitation Program for interns: teamwork and quality of resuscitations. Pediatrics. 2010;125:539-46.

162. Weller J, Civil I, Torrie J, Cumin D, Garden A, Corter A, et al. Can team training make surgery safer? Lessons for national implementation of a simulation-based programme. New Zealand Med J. 2016;129:9-17.

163. Willaert W, Aggarwal R, Bicknell C, Hamady M, Darzi A, Vermassen F, et al. Patient-specific simulation in carotid artery stenting. J Vasc Surg. 2010;52: 1700-5.

164. Yang LY, Yang YY, Huang CC, Liang JF, Lee FY, Cheng HM, et al. Simulationbased inter-professional education to improve attitudes towards collaborative practice: a prospective comparative pilot study in a Chinese medical centre. BMJ Open. 2017;8(7):e015105.

165. Acai A, McQueen SA, Fahim C, Wagner N, McKinnon V, Boston J, et al. "It's not the form; it's the process": a phenomenological study on the use of creative professional development workshops to improve teamwork and communication skills. Med.Humanit. 2016;42:173-80.

166. Agarwal G, Idenouye P, Hilts L, Risdon C. Development of a program for improving interprofessional relationships through intentional conversations in primary care. J Interprof Care. 2008;22:432-5.

167. Amaya-Anas A, Idarraga D, Giraldo V, Gomez LM. Effectiveness of a program for improving teamwork in operating rooms. Rev Colomb Anestesiol. 2015; 43:68-75.

168. Barrett A, Piatek C, Korber S, Padula C. Lessons learned from a lateral violence and team-building intervention. Nurs Adm Q. 2009;33:342-51.

169. Bleakley A, Allard J, Hobbs A. Towards culture change in the operating theatre: embedding a complex educational intervention to improve teamwork climate. Med Teach. 2012;34:e635-40.

170. Blegen MA, Sehgal NL, Alldredge BK, Gearhart S, Auerbach AA, Wachter RM. Improving safety culture on adult medical units through multidisciplinary teamwork and communication interventions: the TOPS Project. Qual Saf Health Care. 2010;19:346-50.

171. Brajtman S, Hall P, Barnes P. Enhancing interprofessional education in endof-life care: an interdisciplinary exploration of death and dying in literature. J Palliat Care. 2009:25:125-31.

172. Brajtman S, Wright D, Hall P, Bush SH, Bekele E. Toward better care of delirious patients at the end of life: a pilot study of an interprofessional educational intervention. J Interprof Care. 2012;26:422-5.
173. Brandler TC, Laser J, Williamson AK, Louie J, Esposito MJ. Team-based learning in a pathology residency training program. Am J Clin Pathol. 2014; 142:23-8.

174. Chan BC, Perkins D, Wan Q, Zwar N, Daniel C, Crookes P, et al. Finding common ground? Evaluating an intervention to improve teamwork among primary health-care professionals. Int J Qual Health Care. 2010;22:519-24.

175. Christiansen MF, Wallace A, Newton JM, Caldwell N, Mann-Salinas E. Improving teamwork and resiliency of burn center nurses through a standardized staff development program. J Burn Care Res. 2017;38:e708-14.

176. Chiocchio F, Rabbat F, Lebel P. Multi-level efficacy evidence of a combined interprofessional collaboration and project management training program for healthcare project teams. Proj.Manag.J. 2015;46:20-34.

177. Cohen EV, Hagestuen R, GonzÃjlez-Ramos G, Cohen HW, Bassich C, Book E, et al. Interprofessional education increases knowledge, promotes team building, and changes practice in the care of Parkinson's disease. Parkinsonism Relat Disord 2016;22:21-27.

178. Cole DC, Giordano CR, Vasilopoulos T, Fahy BG. Resident physicians improve nontechnical skills when on operating room management and leadership rotation. Anesth Analg. 2017;124:300-7.

179. Eklof M, Ahlborg GA. Improving communication among healthcare workers: a controlled study. J.Workplace Learn. 2016;28:81-96.

180. Ellis M, Kell B. Development, delivery and evaluation of a team building project. LEADERSHIP HEALTH SERV (1751-1879) 2014;27:51-66.

181. Ericson-Lidman E, Strandberg G. Care providers learning to deal with troubled conscience through participatory action research. Action Research. 2013;11:386-402.

182. Fallowfield L, Langridge C, Jenkins V. Communication skills training for breast cancer teams talking about trials. Breast. 2014;23:193-7.

183. Fernandez R, Pearce M, Grand JA, Rench TA, Jones KA, Chao GT, et al. A randomized comparison study to evaluate the effectiveness of a computerbased teamwork training intervention on medical teamwork and patient care performance. Acad Emerg Med. 2013;20:S125.

184. Gibon AS, Merckaert I, Lienard A, Libert Y, Delvaux N, Marchal S, et al. Is it possible to improve radiotherapy team members' communication skills? A randomized study assessing the efficacy of a 38-h communication skills training program. Radiother Oncol. 2013;109:170-7.

185. Gillespie BM, Harbeck E, Kang E, Steel C, Fairweather N, Panuwatwanich K, et al. Effects of a brief team training program on surgical teams nontechnical skills: an interrupted time-series study. Journal of Patient Safety. 2017.

186. Gillespie BM, Steel C, Kang E, Harbeck E, Nikolic K, Fairweather N, et al. Evaluation of a brief team training intervention in surgery: a mixed-methods study. AORN J. 2017;106:513-22.

187. Halverson AL, Andersson JL, Anderson K, Lombardo J, Park CS, Rademaker AW, et al. Surgical team training: the Northwestern Memorial Hospital experience. Arch Surg. 2009;144:107-12

188. Howe JL, Penrod JD, Gottesman E, Bean A, Kramer BJ. The rural interdisciplinary team training program: a workforce development workshop to increase geriatrics knowledge and skills for rural providers. Gerontol Geriatr Educ. 2018 Mar;27:1-13.

189. Kelm DJ, Ridgeway JL, Gas BL, Mohan M, Cook DA, Nelson DR, et al. Mindfulness meditation and interprofessional cardiopulmonary resuscitation: a mixed-methods pilot study. Teach Learn Med. 2018 May;18:1-11.

190. Khanna N, Shaya FT, Gaitonde P, Abiamiri A, Steffen B, Sharp D. Evaluation of PCMH model adoption on teamwork and impact on patient access and safety. J Prim Care Community Health. 2017:8:77-82.

191. Korner M, Luzay L, Plewnia A, Becker S, Rundel M, Zimmermann L, et al. A cluster-randomized controlled study to evaluate a team coaching concept for improving teamwork and patient-centeredness in rehabilitation teams. PLOS ONE. 2017;12.

192. Lavoie-Tremblay M, O'Connor P, Biron A, Lavigne GL. Frã@chette J, Briand $A$. The effects of the transforming care at the bedside program on perceived team effectiveness and patient outcomes. Health Care Manag. 2017;36:10-20.

193. Lee P, Allen K, Daly M. A 'Communication and patient safety' training programme for all healthcare staff: can it make a difference? BMJ Qual.Saf. 2012 Jan;21:84-8.

194. Ling L, Gomersall CD, Samy W, Joynt GM, Leung CC, Wong WT, et al. The Effect of a freely available flipped classroom course on health care worker patient safety culture: a prospective controlled study. J Med Internet Res. 2016;18:e180 
195. Lundén M, Lundgren SM, Morrison-Helme M, Lepp M. Professional development for radiographers and post graduate nurses in radiological interventions: building teamwork and collaboration through drama. Radiography. 2017;23:330-6.

196. Mager DR, Lange J. Teambuilding across healthcare professions: the ELDER project. Appl Nurs Res. 2014;27:141-3.

197. Magrane D, Khan O, Pigeon Y, Leadley J, Grigsby RK. Learning about teams by participating in teams. Acad Med. 2010;85:1303-11.

198. Nancarrow SA, Smith T, Ariss S, Enderby PM. Qualitative evaluation of the implementation of the Interdisciplinary Management Tool: a reflective tool to enhance interdisciplinary teamwork using Structured, Facilitated Action Research for Implementation. Health Soc Care Community. 2015;23:437-48.

199. Prewett MS, Brannick MT, Peckler B. Training teamwork in medicine: an active approach using role play and feedback. J Appl Soc Psychol. 2013;43:316-28.

200. Stephens T, Hunningher A, Mills H, Freeth D. An interprofessional training course in crises and human factors for perioperative teams. J. Interprofessional Care. 2016;30:685-8.

201. Webb AR, Young RA, Baumer JG. Emotional intelligence and the ACGME Competencies. J Grad Med Educ. 2010;2:508-12.

202. Beckett CD, Kipnis G. Collaborative communication: integrating SBAR to improve quality/patient safety outcomes. J Healthc Qual. 2009:31:19-28.

203. Clark E, Squire S, Heyme A, Mickle ME, Petrie E. The PACT Project: improving communication at handover. Med J Aust 2009:190:S125-S127.

204. Costa C, Lusk P. Perceptions of interdisciplinary communication among correctional health care providers. J Correct Health Care. 2017;23:122-30.

205. Donahue M, Miller M, Smith L, Dykes P, Fitzpatrick JJ. A leadership initiative to improve communication and enhance safety. Am J Med Qual. 2011;26: 206-11

206. Martin HA, Ciurzynski SM. Situation, background, assessment, and recommendation-guided huddles improve communication and teamwork in the emergency department. J Emerg Nurs. 2015 Nov;41:484-8.

207. Randmaa M, Martensson G, Swenne CL, Engstrom M. SBAR improves communication and safety climate and decreases incident reports due to communication errors in an anaesthetic clinic: a prospective intervention study. BMJ Open 2014;4(1)

208. Renz SM, Boltz MP, Wagner LM, Capezuti EA, Lawrence TE. Examining the feasibility and utility of an SBAR protocol in long-term care. Geriatr Nurs. 2013;34(4):295-301.

209. Rice K, Zwarenstein M, Conn LG, Kenaszchuk C, Russell A, Reeves S. An intervention to improve interprofessional collaboration and communications: a comparative qualitative study. J.Interprofessional Care. 2010 Jul;24:350-61.

210. Sculli GL, Fore AM, Sine DM, Paull DE, Tschannen D, Aebersold M, et al. Effective followership: a standardized algorithm to resolve clinical conflicts and improve teamwork. J Healthc Risk Manag. 2015:35:21-30.

211. Ting WH, Peng FS, Lin HH, Hsiao SM. The impact of situation-backgroundassessment-recommendation (SBAR) on safety attitudes in the obstetrics department. Taiwanese J Obstet Gynecol. 2017;56:171-4.

212. Weller JM, Torrie J, Boyd M, Frengley R, Garden A, Ng WL, et al. Improving team information sharing with a structured call-out in anaesthetic emergencies: a randomized controlled trial. Br J Anaesth. 2014;112:1042-9.

213. Bliss LA, Ross-Richardson C, Sanzari L, Shapiro DS, Lukianoff $A E$, Bernstein BA, et al. Thirty-day outcomes support implementation of a surgical safety checklist. J Am Coll Surg. 2012;215:766-76.

214. Böhmer A, Wappler F, Tinschmann T, Kindermann P, Rixen D, Bellendir M, et al. The implementation of a perioperative checklist increases patients' perioperative safety and staff satisfaction. Acta Anaesthesiol Scand. 2012;56(3):332-8.

215. Böhmer $A B$, Kindermann $P$, Schwanke $U$, Bellendir $M$, Tinschmann $T$, Schmidt $C$, et al. Long-term effects of a perioperative safety checklist from the viewpoint of personnel. Acta Anaesthesiol Scand. 2013;57:150-7.

216. Cabral RA, Eggenberger T, Keller K, Gallison BS, Newman D. Use of a surgical safety checklist to improve team communication. AORN J. 2016;104:206-16.

217. Calland JF, Turrentine FE, Guerlain S, Bovbjerg V, Poole GR, Lebeau K, et al. The surgical safety checklist: lessons learned during implementation. Am Surg. 2011;77:1131-7.

218. Dabholkar Y, Velankar H, Suryanarayan S, Dabholkar TY, Saberwal AA, Verma B. Evaluation and customization of WHO Safety Checklist for patient safety in otorhinolaryngology. Indian j.otolaryngol.head neck surg. 2018;70:149-55.

219. Dubois H, Schmidt PT, Creutzfeldt J, Bergenmar M. Person-centered endoscopy safety checklist: development, implementation, and evaluation. World J Gastroenterol. 2017;23:8605-14.
220. Erestam S, Haglind E, Bock D, Andersson AE, Angenete E. Changes in safety climate and teamwork in the operating room after implementation of a revised WHO checklist: a prospective interventional study. Patient Saf Surg. 2017;11.

221. Everett TC, Morgan PJ, Brydges R, Kurrek M, Tregunno D, Cunningham L, et al. The impact of critical event checklists on medical management and teamwork during simulated crises in a surgical daycare facility. Anaesthesia. 2017;72:350-8.

222. Gordon BM, Lam TS, Bahjri K, Hashmi A, Kuhn MA. Utility of preprocedure checklists in the congenital cardiac catheterization laboratory. Congenit Heart Dis. 2014;9:131-7.

223. Hardy JB, Gouin A, Damm C, CompÃ re V, Veber B, Dureuil B. The use of a checklist improves anaesthesiologistsâ $€^{\mathrm{TM}}$ technical and non-technical performance for simulated malignant hyperthermia management. Anaesth Crit Care Pain Med 2018:37:17-23.

224. Haugen K. A quasi-experimental study of the relationship between safety training and student safety culture perception and error reporting: University of Phoenix; 2013.

225. Haynes AB, Weiser TG, Berry WR, Lipsitz SR, Breizat AHS, Dellinger EP, et al. Safety attitude and relationship to decreased postoperative morbidity and mortality following implementation of a checklist-based surgical safety intervention. BMJ Qual Safety. 2011;20(1):102-7.

226. Helmiö P, Blomgren K, Takala A, Pauniaho SL, Takala RSK, Ikonen TS. Towards better patient safety: WHO Surgical Safety Checklist in otorhinolaryngology. Clin Otolaryngol. 2011;36:242-7.

227. Jing J, Honey ML. Using a checklist in robotic-assisted laparoscopic radical prostatectomy procedures. AORN J. 2016;104:145-52.

228. Kawano T, Taniwaki M, Ogata K, Sakamoto M, Yokoyama M. Improvement of teamwork and safety climate following implementation of the WHO surgical safety checklist at a university hospital in Japan. J Anesth. 2014;28: 467-70.

229. Kearns RJ, Uppal V, Bonner J, Robertson J, Daniel M, McGrady EM. The introduction of a surgical safety checklist in a tertiary referral obstetric centre. BMJ Qual Saf. 2011;20(9):818-22.

230. Kherad O, Restellini S, Menard C, Martel M, Barkun A. Implementation of a checklist before colonoscopy: a quality improvement initiative. Endoscopy. 2018;50:203-10.

231. Lepanluoma M, Takala R, Kotkansalo A, Rahi M, Ikonen TS. Surgical safety checklist is associated with improved operating room safety culture, reduced wound complications, and unplanned readmissions in a pilot study in neurosurgery. Scand.J.Surg. 2014;103:66-72.

232. Low DK, Reed MA, Geiduschek JM, Martin LD. Striving for a zero-error patient surgical journey through adoption of aviation-style challenge and response flow checklists: a quality improvement project. Paediatr Anaesth. 2013:23:571-8.

233. Merrell SB, Gaba DM, Agarwala AV, Cooper JB, Nevedal AL, Asch SM, et al. Use of an emergency manual during an intraoperative cardiac arrest by an interprofessional team: a positive-exemplar case study of a new patient safety tool. Jt Comm J Qual Patient Saf. 2018;44(8):477-84.

234. Mohammed A, Wu J, Biggs T, Ofili-Yebovi D, Cox M, Pacquette S, et al. Does use of a World Health Organization obstetric safe surgery checklist improve communication between obstetricians and anaesthetists? A retrospective study of 389 caesarean sections. BJOG: An International Journal of Obstetrics \& Gynaecology. 2013;120(5):644-8.

235. Molina G, Jiang W, Edmondson L, Gibbons L, Huang LC, Kiang MV, et al. Implementation of the Surgical Safety Checklist in South Carolina Hospitals is associated with improvement in perceived perioperative safety. J Am Coll Surg. 2016;222:725-736e5.

236. Nilsson L, Lindberget O, Gupta A, Vegfors M. Implementing a pre-operative checklist to increase patient safety: a 1-year follow-up of personnel attitudes. Acta Anaesthesiol Scand. 2010;54(2):176-82.

237. Norton EK, Rangel SJ. Implementing a pediatric surgical safety checklist in the OR and beyond. AORN J. 2010;92:61-71.

238. Papaconstantinou HT, Jo CH, Reznik SI, Smythe WR, Wehbe-Janek H. Implementation of a surgical safety checklist: impact on surgical team perspectives. Ochsner J. 2013;13:299-309.

239. Sewell M, Adebibe M, Jayakumar P, Jowett C, Kong K, Vemulapalli K, et al. Use of the WHO surgical safety checklist in trauma and orthopaedic patients. Int Orthop. 2011 Jun;35:897-901.

240. Takala RSK, Pauniaho SL, Kotkansalo A, Helmio P, Blomgren K, Helminen M, et al. A pilot study of the implementation of WHO Surgical Checklist in 
Finland: improvements in activities and communication. Acta Anaesthesio Scand. 2011;55:1206-14.

241. Tscholl DW, Weiss M, Kolbe M, Staender S, Seifert B, Landert D, et al. An anesthesia preinduction checklist to improve information exchange, knowledge of critical information, perception of safety, and possibly perception of teamwork in anesthesia teams. Anesth Analg. 2015;121:948-56.

242. Urbach DR, Govindarajan A, Saskin R. Introduction of surgical safety checklists in Ontario. Mass Medical Soc: Canada; 2014.

243. White MC, Peterschmidt J, Callahan J, Fitzgerald JE, Close KL. Interval follow up of a 4-day pilot program to implement the WHO surgical safety checklist at a Congolese hospital. Globalization Health. 2017;13.

244. Berenholtz SM, Schumacher K, Hayanga AJ, Simon M, Goeschel C, Pronovost $P J$, et al. Implementing standardized operating room briefings and debriefings at a large regional medical center. Jt Comm J Qual Patient Saf. 2009;35:391-7

245. Boet S, Bould MD, Bruppacher HR, Desjardins F, Chandra DB, Naik VN. Looking in the mirror: self-debriefing versus instructor debriefing for simulated crises. Crit Care Med. 2011;39(6):1377-81.

246. Boet S, Dylan Bould M, Sharma B, Revees S, Naik VN, Triby E, et al. Withinteam debriefing versus instructor-led debriefing for simulation-based education: a randomized controlled trial. Ann Surg. 2013;258:53-8.

247. Einav Y, Gopher D, Kara I, Ben-Yosef O, Lawn M, Laufer N, et al. Preoperative briefing in the operating room: shared cognition, teamwork, and patient safety. Chest. 2010;137:443-9.

248. Gleicher Y, Mosko JD, McGhee I. Improving cardiac operating room to intensive care unit handover using a standardised handover process. BMJ open qual. 2017;6:e000076.

249. Howe EE. Empowering certified nurse's aides to improve quality of work life through a team communication program. Geriatr Nurs. 2014;35:132-6.

250. Khoshbin A, Lingard L, Wright JG. Evaluation of preoperative and perioperative operating room briefings at the Hospital for Sick Children. Can J Surg. 2009;52:309-15.

251. Lingard L, Regehr G, Orser B, Reznick R, Baker GR, Doran D, et al. Evaluation of a preoperative checklist and team briefing among surgeons, nurses, and anesthesiologists to reduce failures in communication. Archives of surgery. 2008;143(1):12-8.

252. McLaughlin N, Winograd D, Chung HR, Wiele VD, Martin NA. Impact of the time-out process on safety attitude in a tertiary neurosurgical department. World Neurosurg. 2014;82:567-74.

253. Nadler I, Sanderson PM, Van Dyken CR, Davis PG, Liley HG. Presenting video recordings of newborn resuscitations in debriefings for teamwork training. BMJ Qual Saf. 2011;20:163-9.

254. Nundy S, Mukherjee A, Sexton JB, Pronovost PJ, Knight A, Rowen LC, et al. Impact of preoperative briefings on operating room delays: a preliminary report. Arch Surg. 2008;143:1068-72.

255. Paige JT, Aaron DL, Yang T, Howell DS, Chauvin SW. Improved operating room teamwork via SAFETY prep: a rural community hospital's experience. World J Surg. 2009;33:1181-7.

256. Pannick S, Athanasiou T, Long SJ, Beveridge I, Sevdalis N. Translating staff experience into organisational improvement: The HEADS-UP stepped wedge, cluster controlled, non-randomised trial. BMJ Open. 2017;7.

257. Papaspyros SC, Javangula KC, Prasad Adluri RK, O'Regan DJ. Briefing and debriefing in the cardiac operating room. Analysis of impact on theatre team attitude and patient safety. Interactive cardiovascular and thoracic surgery. 2010;10(1):43-7.

258. Skåre C, Calisch TE, Saeter E, Rajka T, Boldingh AM, Nakstad B, et al. Implementation and effectiveness of a video-based debriefing programme for neonatal resuscitation. Acta Anaesthesiol Scand. 2018;62:394-403.

259. Steinemann S, Bhatt A, Suares G, Wei A, Ho N, Kurosawa G, et al. Trauma team discord and the role of briefing. J.Trauma Acute Care Surg. 2016;81: 184-189.

260. Wagner LM, Huijbregts M, Sokoloff LG, Wisniewski R, Walsh L, Feldman S, et al. Implementation of mental health huddles on dementia care units. Can J Aging. 2014;33:235-45.

261. Weiss M, Kolbe M, Grote G, Spahn DR, Grande B. Why didn't you say something? Effects of after-event reviews on voice behaviour and hierarchy beliefs in multi-professional action teams. Eur.J.Work Organ.Psychol. 2017;26: 66-80.

262. Whyte S, Lingard L, Espin S, Baker GR, Bohnen J, Orser BA, et al. Paradoxical effects of interprofessional briefings on OR team performance. Cognition. Technology and Work. 2008;10(4):287-94.
263. Zausig Y, Grube C, Boeker-Blum T, Busch C, Bayer Y, Sinner B, et al. Inefficacy of simulator-based training on anaesthesiologists' non-technical skills. Acta Anaesthesiol Scand. 2009;53(5):611-9.

264. Genet IC, Firestone KS, Volsko TA. Neonatal respiratory therapist-led rounds can improve staff satisfaction and timeliness of respiratory interventions. Respir Care. 2015;60:321-7.

265. Henkin S, Chon TY, Christopherson ML, Halvorsen AJ, Worden LM, Ratelle JT. Improving nurse-physician teamwork through interprofessional bedside rounding. J Multidiscip Healthc. 2016;9:201-5.

266. Li J, Talari P, Kelly A, Latham B, Dotson S, Manning K, et al. Interprofessional Teamwork Innovation Model (ITIM) to promote communication and patient-centred, coordinated care. BMJ Quality and Safety. 2018;27(9):700-9.

267. O'Leary KJ, Wayne DB, Haviley C, Slade ME, Lee J, Williams MV. Improving teamwork: impact of structured interdisciplinary rounds on a medical teaching unit. J Gen Intern Med. 2010;25:826-32.

268. O'Leary KJ, Haviley C, Slade ME, Shah HM, Lee J, Williams MV. Improving teamwork: impact of structured interdisciplinary rounds on a hospitalist unit. J Hosp Med. 2011;6:88-93.

269. O'Leary KJ, Killarney A, Hansen LO, Jones S, Malladi M, Marks K, et al. Effect of patient-centred bedside rounds on hospitalised patients' decision control, activation and satisfaction with care. BMJ Quality and Safety. 2015; 25(12):921-8.

270. Young E, Paulk J, Beck J, Anderson M, Burck M, Jobman L, et al. Impact of altered medication administration time on interdisciplinary bedside rounds on academic medical ward. J Nurs Care Qual. 2017;32:218-25.

271. Butler L, Whitfill T, Wong AH, Gawel M, Crispino L, Auerbach M. The impact of telemedicine on teamwork and workload in pediatric resuscitation: a Simulation-Based, Randomized Controlled Study, vol. 29; 2018.

272. Chu-Weininger M, Wueste L, Lucke JF, Weavind L, Mazabob J, Thomas EJ. The impact of a tele-ICU on provider attitudes about teamwork and safety climate. Qual Saf Health Care. 2010;19:e39.

273. Doyle C, Jackson D, Loi S, Malta S, Moore K. Videoconferencing and telementoring about dementia care: evaluation of a pilot model for sharing scarce old age psychiatry resources. Int Psychogeriatr. 2016;28:1567-74.

274. Foo E, McDonald R, Savage E, Floyd R, Butler A, Rumball-Smith A, et al. Mobile task management tool that improves workflow of an acute general surgical service. ANZ J Surg. 2015;85:760-5.

275. Letchworth PM, Duffy SP, Phillips D. Improving non-technical skills (teamwork) in post-partum haemorrhage: a grouped randomised trial. Eur J Obstet Gynecol Reprod Biol. 2017;217:154-60.

276. O'Connor C, Friedrich JO, Scales DC, Adhikari NKJ. The use of wireless e-mail to improve healthcare team communication. J Am Med Informatics Assoc. 2009:16:705-13.

277. Yeh PH, Hung SK, Lee MS, Chiou WY, Lai CL, Tsai WT, et al. Implementing web-based ping-pong-type e-communication to enhance staff satisfaction, multidisciplinary cooperation, and clinical effectiveness A SQUIRE-compliant quality-improving study. Medicine. 2016;95(44).

278. Aberdeen SM, Byrne G. Concept mapping to improve team work, team learning and care of the person with dementia and behavioural and psychological symptoms. Dement.-Int.J.soc.Res.Pract. 2018;17:279-96.

279. Ainsworth CR, Pamplin JC, Rn DAA, Linfoot JA, Chung KK. A bedside communication tool did not improve the alignment of a multidisciplinary team's goals for intensive care unit patients. J Crit Care. 2013;28:112.e7-112.e13.

280. Bennett AH, Hassinger JA, Martin LA, Harris LH, Gold M. Developing patientcentered teams: the role of sharing stories about patients and patient care. Fam Syst Health. 2015;33:203-12.

281. Daley K, Richardson J, James I, Chambers A, Corbett D. Clinical dashboard: use in older adult mental health wards. Psychiatr. 2013;37:85-8.

282. O'Neil T, Lyndale P, Szakatis K, Fitzgerald T. The value of a brief thought for the day reflection on an academic consult service. Am J Hosp Palliat Care. 2017:34:869-73.

283. Siegele P. Enhancing outcomes in a surgical intensive care unit by implementing daily goals tools. Crit Care Nurse. 2009;29:58-70 13p.

284. Stoller JK, Sasidhar M, Wheeler DM, Chatburn RL, Bivens RT, Priganc D, et al. Team-Building and change management in respiratory care: description of a process and outcomes. Respir Care. 2010;55:741-8.

285. Barry CN, Abraham KM, Weaver KR, Bowersox NW. Innovating team-based outpatient mental health care in the Veterans Health Administration: staffperceived benefits and challenges to pilot implementation of the Behavioral Health Interdisciplinary Program (BHIP). Psychol Serv. 2016;13: 148-55. 
286. de Beijer AE, Hansen TB, Stilling M, Jakobsen F. Staff perception of interprofessional working relationships after a work redesign intervention in a Danish orthopaedic hand unit outpatient clinic. J.Interprofessional Care. 2016;30:149-55.

287. Clements A, Curtis K, Horvat L, Shaban RZ. The effect of a nurse team leader on communication and leadership in major trauma resuscitations. Int Emerg Nurs. 2015;23:3-7.

288. Deneckere S, Euwema M, Lodewijckx C, Panella M, Mutsvari T, Sermeus W, et al. Better interprofessional teamwork, higher level of organized care, and lower risk of burnout in acute health care teams using care pathways: a cluster randomized controlled trial. Med Care. 2013;51:99-107.

289. Fernandez R, Tran DT, Johnson M, Jones S. Interdisciplinary communication in general medical and surgical wards using two different models of nursing care delivery. J Nurs Manage. 2010;18:265-74.

290. Fogel BN, Warrick S, Finkelstein JA, Klein M. Change in residents' experience in continuity clinic after patient-focused primary care redesign. Acad Pediatr. 2016;16(7):616-20.

291. Frykman M, Hasson H, Athlin Ã, von TS. Functions of behavior change interventions when implementing multi-professional teamwork at an emergency department: a comparative case study. BMC Health Serv Res. 2014;14:218.

292. Greene J, Kurtzman ET, Hibbard JH, Overton V. Working under a clinic-leve quality incentive: primary care clinicians' perceptions. Ann.Fam.Med. 2015; 13:235-41.

293. Hern T, Talen M, Babiuch C, Durazo-Arvizu R. Patient care management teams: improving continuity, office efficiency, and teamwork in a residency clinic. J Grad Med Educ. 2009;1:67-72.

294. Hung DY, Harrison MI, Truong Q, Du X. Experiences of primary care physicians and staff following lean workflow redesign. BMC Health Serv Res. 2018;10(18):274.

295. O'Leary KJ, Wayne DB, Landler MP, Kulkarni N, Haviley C, Hahn KJ, et al. Impact of localizing physicians to hospital units on nurse-physician communication and agreement on the plan of care. J Gen Intern Med. 2009:24:1223-7.

296. Pan XH, Zhang J, Dai C, Si YB. The effect of instructional supervision by an operating room assistant on first-case starts. J.PeriAnesthesia Nurs. 2017;32: 58-65.

297. Parush A, Mastoras G, Bhandari A, Momtahan K, Day K, Weitzman B, et al. Can teamwork and situational awareness $(S A)$ in ED resuscitations be improved with a technological cognitive aid? Design and a pilot study of a team situation display. J Biomed Informatics. 2017;76:154-61.

298. Pati D, Harvey TEJ, Redden P, Summers B, Pati S. An empirical examination of the impacts of decentralized nursing unit design. HERD. 2015;8:56-70.

299. Stavroulis A, Cutner A, Liao LM. Staff perceptions of the effects of an integrated laparoscopic theatre environment on teamwork. Gynecol Surg. 2013;10:177-80.

300. Stepaniak PS, Heij C, Buise MP, Mannaerts GHH, Smulders JF, Nienhuijs SW. Bariatric surgery with operating room teams that stayed fixed during the day: a multicenter study analyzing the effects on patient outcomes, teamwork and safety. Climate, and Procedure Duration. Anesth Analg. 2012; 115:1384-92.

301. Basson T, Montoya A, Neily J, Harmon L, Watts BV. Improving patient safety culture: a report of a multifaceted intervention. Journal of Patient Safety. 2018.

302. Bunnell CA, Gross AH, Weingart SN, Kalfin MJ, Partridge A, Lane S, et al. High performance teamwork training and systems redesign in outpatient oncology. BMJ Qual Saf. 2013:22:405-13.

303. Braithwaite J, Westbrook M, Nugus P, Greenfield D, Travaglia J, Runciman W, et al. A four-year, systems-wide intervention promoting interprofessional collaboration. BMC Health Serv Res. 2012;12:99.

304. Carney BT, West P, Neily J, Mills PD, Bagian JP. Changing perceptions of safety climate in the operating room with the Veterans Health Administration medical team training program. Am J Med Qual. 2011;26: 181-4.

305. Carney BT, West P, Neily JB, Mills PD, Bagian JP. Improving perceptions of teamwork climate with the Veterans Health Administration medical team training program. Am J Med Qual. 2011;26:480-4.

306. Costello J, Clarke C, Gravely G, D'Agostino-Rose D, Puopolo R. Working together to build a respectful workplace: transforming OR culture. AORN J. 2011;93(1):115-26.
307. Ginsburg L, Bain L. The evaluation of a multifaceted intervention to promote "speaking up" and strengthen interprofessional teamwork climate perceptions. J Interprof Care. 2017;31:207-17.

308. Hilts L, Howard M, Price D, Risdon C, Agarwal G, Childs A. Helping primary care teams emerge through a quality improvement program. Fam Pract. 2013;30:204-11.

309. Hsu YJ, Marsteller JA. Influence of the comprehensive unit-based safety program in ICUs: evidence from the Keystone ICU project. American Journal of Medical Quality. 2015;31(4):349-57.

310. Hsu YC, Jerng JS, Chang CW, Chen LC, Hsieh MY, Huang SF, et al. Integrating team resource management program into staff training improves staff's perception and patient safety in organ procurement and transplantation: the experience in a university-affiliated medical center in Taiwan. BMC Surg. 2014;14:51.

311. Je SM, Kim HJ, You JS, Chung SP, Cho J, Lee JH, et al. Assessing safety attitudes among healthcare providers after a hospital-wide high-risk patient care program. Yonsei Med J. 2014 Mar;55:523-9.

312. Kotecha J, Brown JB, Han H, Harris SB, Green M, Russell G, et al. Influence of a quality improvement learning collaborative program on team functioning in primary healthcare. Fam Syst Health. 2015 Sep;33:222-30.

313. Lin DM, Carson KA, Lubomski LH, Wick EC, Pham JC. Statewide collaborative to reduce surgical site infections: results of the Hawaii Surgical Unit-Based Safety Program. J Am Coll Surg. 2018

314. McArdle J, Sorensen A, Fowler Cl, Sommerness S, Burson K, Kahwati L. Strategies to improve management of shoulder dystocia under the AHRQ Safety Program for Perinatal Care. J Obstet Gynecol Neonatal Nurs. 2018 Mar;47:191-201.

315. McCulloch P, Morgan L, New S, Catchpole K, Roberston E, Hadi M, et al. Combining systems and teamwork approaches to enhance the effectiveness of safety improvement interventions in surgery. Ann Surg. 2017;265(1):90-6.

316. Neily J, Mills PD, Lee P, Carney B, West P, Percarpio K, et al. Medical team training and coaching in the Veterans Health Administration; assessment and impact on the first 32 facilities in the programme. Qual Saf Health Care. 2010;19:360-4

317. Pettker CM, Thung SF, Raab CA, Donohue KP, Copel JA, Lockwood CJ, et al. A comprehensive obstetrics patient safety program improves safety climate and culture. Obstet Gynecol. 2011;204:216.e1-6.

318. Pitts SI, Maruthur NM, Luu NP, Curreri K, Grimes R, Nigrin C, et al. Implementing the Comprehensive Unit-Based Safety Program (CUSP) to improve patient safety in an academic primary care practice. Jt Comm J Qual Patient Saf. 2017:43:591-7.

319. Pronovost PJ, Berenholtz SM, Goeschel C, Thom I, Watson SR, Holzmueller CG, et al. Improving patient safety in intensive care units in Michigan. J Crit Care. 2008;23:207-21.

320. Sexton JB, Berenholtz SM, Goeschel CA, Watson SR, Holzmueller CG, Thompson DA, et al. Assessing and improving safety climate in a large cohort of intensive care units. Crit Care Med. 2011:39:934-9.

321. Stapley E, Sharples E, Lachman P, Lakhanpaul M, Wolpert M, Deighton J. Factors to consider in the introduction of huddles on clinical wards: perceptions of staff on the SAFE programme. Int J Qual Health Care. 2018; 30:44-9.

322. Timmel J, Kent PS, Holzmueller CG, Paine L, Schulick RD, Pronovost PJ. Impact of the Comprehensive Unit-based Safety Program (CUSP) on safety culture in a surgical inpatient unit. Jt Comm J Qual Patient Saf. 2010;36:252-60.

323. Wolf FA, Way LW, Stewart L. The efficacy of medical team training: improved team performance and decreased operating room delays: a detailed analysis of 4863 cases. Ann Surg. 2010;252:477-83.

324. Lauber JK. Resource management in the cockpit. Air line pilot. 1984;53:20-3.

325. Helmreich RL, Merritt AC, Wilhelm JA. The evolution of crew resource management training in commercial aviation. Int J Aviat Psychol. 1999;9(1): 19-32.

326. Aggarwal R, Mytton OT, Derbrew M. Training and simulation for patient safety. BMJ Quality and Safety. 2010;19(2):i34-43.

327. Lemieux-Charles L, McGuire WL. What do we know about health care team effectiveness? A review of the literature. Med Care Res Rev. 2006:63(3):263-300.

\section{Publisher's Note}

Springer Nature remains neutral with regard to jurisdictional claims in published maps and institutional affiliations. 